\title{
wimp, a dominant maternal-effect mutation, reduces transcription of a specific subset of segmentation genes in Drosophila
}

\author{
Susan M. Parkhurst ${ }^{1}$ and David Ish-Horowicz \\ Developmental Genetics Laboratory, Imperial Cancer Research Fund, Developmental Biology Unit, Zoology Department, \\ University of Oxford, Oxford OX1 3PS, UK
}

\begin{abstract}
wimp is a dominant maternal-effect mutation that interacts with a specific subset of early-acting maternal and zygotic Drosophila genes. We show that wimp is a change-of-function mutation, allelic to mutations of the 140-kD subunit of RNA polymerase, which causes reduced transcription of interacting genes. Loci that do not interact with wimp are expressed at normal levels. We discuss these results in terms of specific interactions between transcription factors and RNA polymerase. Embryos from wimp mothers show unaltered fate maps and develop normally, despite the reduction of transcript levels at least twofold. We suggest that spatial cues are determined by a balance of segmentation gene products rather than their absolute concentrations. We also demonstrate powerful genetic screens for otherwise undetected loci required for segmentation, sex determination, and other early functions.
\end{abstract}

[Key Words: Segmentation gene expression; RNA polymerase; Drosophila maternal-effect mutation; pattern formation; transcription; embryonic fate map]

Received November 27, 1990; revised version accepted December 27, 1990.

Several lines of evidence indicate that anterior-posterior patterning in the Drosophila embryo is regulated predominantly at the transcriptional level. The early development of the Drosophila embryo is marked by its progressive subdivision into increasingly more precise spatial domains, achieved through the actions of a hierarchy of maternal and zygotic segmentation genes (NüssleinVolhard and Wieschaus 1980; for review, see Scott and O'Farrell 1986; Akam 1987; Scott and Carroll 1987; Ingham 1988). These genes have been ranked according to their phenotypes and times of expression and can be subdivided further according to their epistatic interactions: Earlier-acting genes control the patterns and expression of later genes. The maternal genes establish coarse positional cues that define the broad domains of gap gene expression. In turn, the gap genes are needed for the pairrule genes to be expressed in striped domains /Carroll and Scott 1986; Ingham et al. 1986; Frasch and Levine 1987; Pankratz et al. 1989, 1990; Struhl 1989b; Hülskamp et al. 1990|. Such patterns evolve over a period of $\sim 30-60$ min, arguing that most of the segmentation gene products act immediately. Protein and transcript domains correspond well, indicating the predominance of

${ }^{1}$ Present address: Division of Biology 156-29, California Institute of Technology, Pasadena, California 91125 USA. transcriptional control, although post-transcriptional mechanisms may also be involved, particularly in the posterior region of the embryo (Macdonald and Struhl 1986; Gaul et al. 1987; Hülskamp et al. 1989; Irish et al. 1989; Struhl 1989a).

Many segmentation genes encode nuclear proteins with homologies to well-characterized transcription factors. These include proteins with defined DNA-binding motifs: Homeo box domains, "zinc-fingers," "leucine zippers," and helix-loop-helix (b-HLH) motifs (for review, see Levine and Hoey 1988; Biggin and Tjian 1989; Murre et al. 1989; Struhl 1989; Benezra et al. 1990; Hayashi and Scott 1990).

The most direct evidence for transcriptional regulation of segmentation gene expression comes from studies of hunchback $(h b)$ regulation by the anterior morphogen, bicoid $(b c d)$. The bcd protein defines different anteroposterior positions in a concentration-dependent manner (Frohnhöfer and Nüsslein-Volhard 1986, 1987; Driever and Nüsslein-Volhard 1988a). Thus, blastoderm positions of anterior anlagen are sensitive to copy number of maternal $\mathrm{bcd}^{+}$genes (Driever and Nüsslein-Volhard 1988b). Footprinting and in vivo transformation assays indicate that binding of $b c d$ protein to the $h b$ promoter directly controls the domain of $h b$ expression (Driever and Nüsslein-Volhard 1989; Driever et al. 1989; Struhl et al. 1989). 
Further evidence for transcriptional regulation comes from studies of fushi tarazu (ftz) expression using reporter gene fusions. The $f t z$ promoter includes transcriptional activator sites required for expression within stripes and other elements that are needed for $f t z$ autoregulation (Hiromi et al. 1985; Hiromi and Gehring 1987; Dearolf et al. 1989). ftz transcription is also under negative control, including repression between stripes and at the embryonic poles (Hiromi et al. 1985; Edgar et al. 1986).

The precise mechanisms whereby segmentation genes modulate transcription are unclear. Different homeo domain proteins have been shown to recognize similar DNA target sequences, indicating that these proteins may compete for binding sites in vivo (see Levine and Hoey 1988; Hayashi and Scott 1990). Many homeo domain target sequences overlap with or are adjacent to sequence motifs recognized by non-homeo domain transcription factors, suggesting that homeo domain proteins may also compete with other families of regulatory proteins for DNA-binding sites (Odenwald et al. 1989). Homeo box proteins can enhance or repress transcription, depending on cell type and the particular target gene; this suggests that they interact with other, more generally required components of the transcriptional machinery. The b-HLH motif has been proposed to mediate functionally required heterodimer formation, suggesting that the pair-rule gene hairy $(h)$ may also act together with other proteins (Murre et al. 1989; Parkhurst et al. 1990).

The above Drosophila genes were identified because they are specifically required during segmentation (although most are reutilized later in development). Other factors that participate in the regulation of segmentation gene transcription might remain undetected because they are required generally for transcription and lead to apparently unrelated mutant phenotypes, or because they are functionally or structurally redundant. Such factors could include ubiquitous factors such the TATAbinding TFIID factor needed for the transcription of most genes and generalized sequence-specific factors that act on a wide range of genes and are expressed in most cells (Ptashne 1988; Mitchell and Tjian 1989; Parker 1989). Indeed, if the segmentation genes act through such factors, their identification would be critical to understanding how spatially restricted gene expression is achieved. Although general or redundant factors might not be mutable to readily identifiable phenotypes, occasional conditional or tissue-specific alleles that affect only segmentation might be recoverable.

This paper describes the characterization of wimp, one such mutation. We show that wimp is a dominant maternal-effect mutation, allelic to an RNA polymerase II subunit (RpII140), which causes reduced transcription of a specific subset of early-acting genes. Nevertheless, embryos from wimp mothers develop normally. We discuss the implications of locus-specific transcriptional interactions for mechanisms of transcriptional regulation and also present a "gene balance" model for specifying positional cues in the Drosophila embryo. We also demon- strate a genetic screen for novel mutations affecting early gene function.

\section{Results \\ wimp is both a conditional maternal-effect and a recessive lethal mutation}

The wimp allele was identified in a screen for zygotic segmentation genes (Jürgens et al. 1984) and originally designated an allele of the hairy $(h)$ locus on the basis of complementation tests and its homozygous lethal phenotype (see below). However, subsequent experiments showed that this noncomplementation is due to a maternal effect that causes lethality of flies heterozygous for $h$ when derived from a wimp/ + mother (P. Ingham, unpubl.). Figure 1A illustrates the dominant maternal effect: when wimp/ + females are mated to $h /+$ males, both classes of $h$ heterozygous progeny $(h /+$ and $h /$ wimp/ die. In the reciprocal cross using $h /+$ females, heterozygous $h$ embryos survive (Fig. 1B). Although this paper will concentrate on the maternal interaction, we first provide a brief introduction to the wimp locus and its recessive lethality.

The initial classification of wimp as a segmentation gene was based on its homozygous pair-rule phenotype. The phenotype is somewhat variable: The most common phenotype is pair-wise fusions of adjacent denticle belts (Fig. 1C), but some embryos show more severe fusions (Fig. 1D) and, rarely, weaker phenotypes (not shown). However, the pattern defects in homozygous wimp embryos are likely to result from cellularization defects as well as alterations in segmentation gene expression. When staining with antibodies against segmentation proteins, we noticed regions of altered nuclear density and holes in the cell monolayer (Fig. 2A,B). Detailed histological analysis shows that nuclear organization is severely disrupted in homozygous wimp embryos and that their cortical cytoplasm is irregular (cf. Fig. 2C with Fig. 2D-H). Nuclei are often of different sizes, indicative of asynchronous nuclear divisions that often accompany perturbations of nuclear density (Foe and Alberts 1983; Sullivan 1987; Wieschaus and Sweeton 1988).

For the rest of this paper, we use the term "wimp embryos" to refer to maternally affected embryos, that is, embryos from a "wimp" mother (i.e., wimp/ + ). Such $+/+$ or wimp $/+$ embryos are wild type for all other segmentation genes and develop normally unless fertilized with sperm mutant for an interacting locus.

\section{The wimp maternal effect interacts with many genes}

The wimp maternal-effect interaction is not limited to the $h$ locus: flies heterozygous for Krüppel $(K r)$ or evenskipped (eve) are also lethal if derived from wimp mothers (P. Ingham, unpubl.). We have extended this analysis and find that wimp shows genetic interactions with a wide range of genes (summarized in Table 1; discussed in more detail below). These include both zygotic and maternal genes, segmentation genes, and genes not affecting 

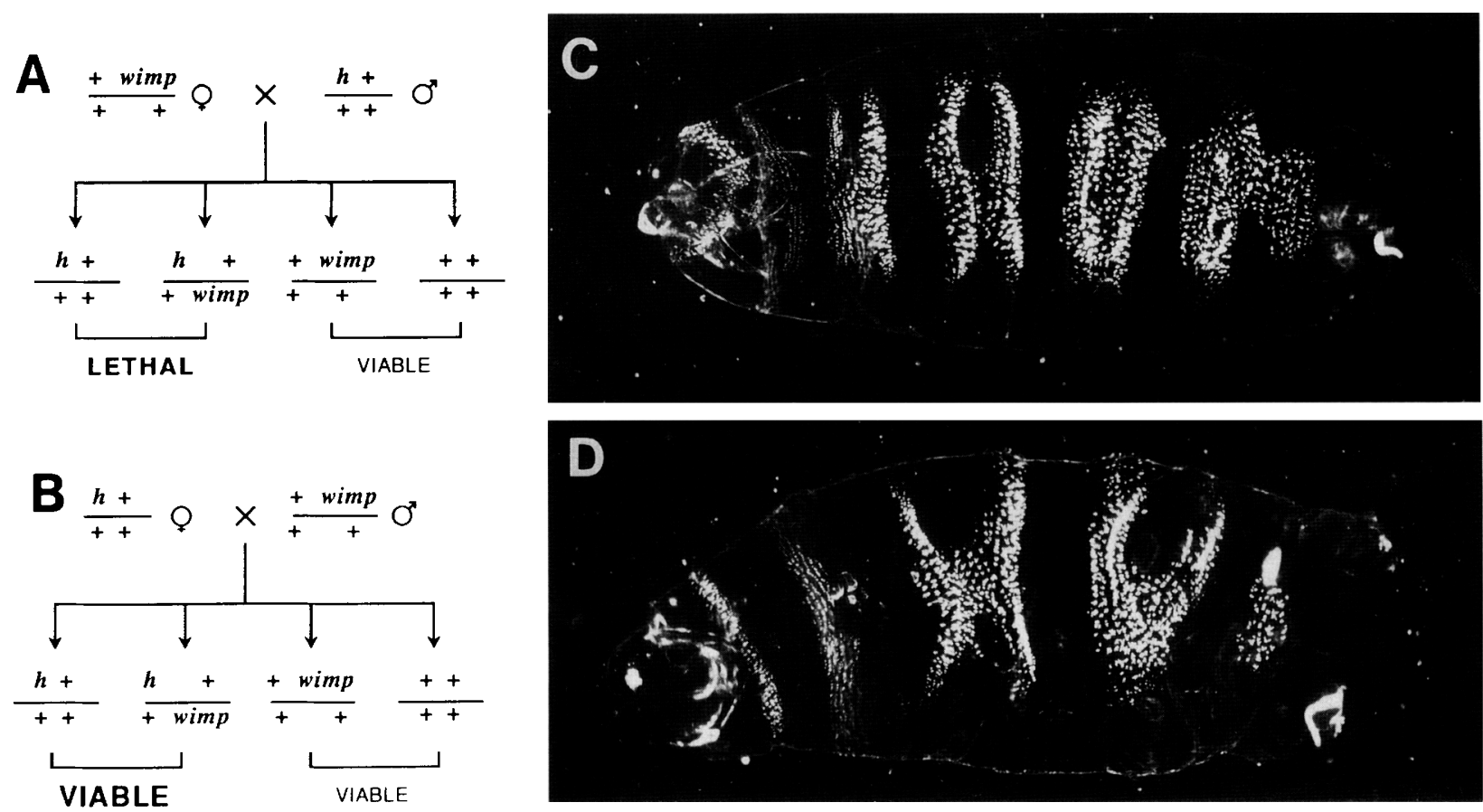

Figure 1. The wimp maternal-effect and recessive lethality. $(A, B)$ Genetic crosses illustrating the interaction between the dominant wimp maternal effect and the zygotically required pair-rule gene $h$. Heterozygous $h$ progeny are embryonic lethal when derived from a wimp/+ mother $(A \mid$. The same two classes of $h$ heterozygous progeny survive if the genotypes of the parents are reversed $(B|| C,. D \mid$ Ventral cuticle phenotype of homozygous wimp larvae showing weak pair-wise fusions $(C)$ and more severe fusions $(D)$. Anterior is to the left.

pattern (Table 1). The broad spectrum of interacting loci is consistent with a general/basic cellular function being affected by the wimp mutation.

Affected embryos show phenotypes characteristic of intermediate alleles of the interacting loci. For example, $h /+$ embryos from wimp/ + mothers resemble pair-rule $\mathrm{h} / \mathrm{h}$ embryos, lacking alternate metameres (Fig. 3A). Similarly, $K r /+$ embryos from wimp mothers show a characteristic gap phenotype (Fig. 3B). This suggests that wimp acts to reduce gene expression.

Most classes of gene shown in Table 1 include both wimp-sensitive and wimp-insensitive loci. For example, the gap genes $h b$ and tailless are insensitive to wimp, while other gap genes, $K r$ and knirps $(k n i)$, are sensitive. Genes that act after blastoderm formation, for example, the segment-polarity genes, appear not to interact with wimp. However, genes that are sensitive or insensitive to wimp are not distinguished merely by dosage sensitivity, as wimp appears not to interact with the extremely haploinsufficient gene decapentaplagic $(d p p)$ (Irish and Gelbart 1987). Nor is there an obvious correlation between time of expression and wimp sensitivity; effects on gene expression can persist past the blastoderm stage (see below and Discussion).

Maternal-effect genes wimp fails to complement several maternal mutations affecting pattern (Fig. 3D; Table 1). For example, females heterozygous for both wimp and bcd (+ wimp/bcd + females) produce embryos with an intermediate bcd phenotype in which head and thoracic structures are largely lacking (Fig. 3C). wimp also interacts with the dorsal (dl) gene, which encodes a nuclear protein that acts as the dorsoventral morphogen (Steward 1987; Steward et al. 1988). Interestingly, wimp does not interact with posterior genes [e.g., nanos (nos)] that appear to act in a very different manner from $b c d$ and $d 1$ (Nüsslein-Volhard et al. 1987; Lehmann 1988; Hülskamp et al. 1989; Irish et al. 1989; Struhl 1989a).

wimp also interacts with genes required for sex determination. Female embryos from homozygous daughterless $(d a)$ mothers die because they fail to activate the Sex-lethal (SxI) gene (Cline 1980). Similarly, most female progeny die from $d a /+$; wimp/+ mothers: $86 \%$ (567) 656) of adult progeny are male. The (presumed) female embryos die, some with poorly developed cuticles resembling those of female embryos mutant for $S x l$.

Zygotic genes The wimp maternal effect interacts with members of both the gap and pair-rule zygotic segmentation gene classes (Table 1). The lethal embryos display cuticular phenotypes characteristic of homozygous segmentation mutant embryos (e.g., Fig. 3A,B). Embryos heterozygous for the gap gene $k n i$ and the pair-rule genes paired (prd) and odd-paired (opa) are not completely lethal. Of the expected heterozygous progeny, $80 \%$ (kni), $5 \%$ (prd), and $52 \%$ (opa) eclose as adults, although survivors have defective or missing structures such as fused/missing segments or legs (see footnote to Table 1). 
The dorsoventral genes, twist (twi) and snail (sna) also interact with the wimp maternal effect, although with reduced penetrance. Approximately $40 \%$ and $55 \%$ of such embryos show twi- or sna-like cuticular phenotype, respectively (not shown). The remaining heterozygous progeny hatch and develop into apparently normal adults. Either these embryos retain sufficient twi and sna activity to allow survival or the lethality is an indirect consequence of reduced $d l$ expression (see below). Both twi and sna have been shown to be sensitive to reduced $d l$ dosage (Simpson 1983; Nüsslein-Volhard and Roth 1989; Roth et al. 1989).

wimp also interacts with $S \mathrm{xl}$ and two zygotic genes implicated in $S x l$ initiation, sisterless- $a$ and sisterless- $b$ (Cline 1986, 1988), causing female-specific lethality of heterozygous female progeny. wimp interferes with a process that is used in sex determination as well as segmentation.

\section{Protein levels are reduced in wimp embryos}

The dominant lethality and lethal phenotypes caused by the wimp maternal effect are most simply explained if wimp causes reduced expression of susceptible loci. Figure 4, A-D, shows that the levels of $f t z$ and $K r$ proteins are indeed reduced in wimp embryos, although their patterns are unchanged (see also eve in Fig. 7D-F, below). A ftz-lacZ reporter gene (Hiromi et al. 1985) is similarly affected (Fig. 5A-D). Lowered expression persists during germ-band extension when continued transcription is under autoregulatory control (Fig. 5C,D). $h$ expression is similarly affected in wimp embryos (not shown). (For discussion of the effects on $b c d$, see below.)

Protein levels are further reduced in embryos heterozygous for interacting mutations, indicating that their lethality is due to insufficient expression. $f t z$ expression in wimp embryos that contain only one wild-type $f t z$ gene is either undetectable (Fig. 4E) or weak and disorganized (Fig. 4F). The extreme reduction in $f t z$ expression leads to disruption or lack of the ftz-requiring even-numbered engrailed (en) stripes (Fig. 4G,H). Although en pat-

Figure 2. The homozygous wimp embryonic phenotypes. Dorsal surface of wimp/wimp embryos stained with anti-ftz $(A)$ or anti-en $(B)$ show that the pattern of staining is disrupted due to large regions devoid of nuclei. Tissue sections of wild-type $(C)$ and homozygous wimp $(D-H)$ embryos are shown at the blastoderm stage. The uniform layer of nuclei and cytoplasm appears very uneven in homozygous wimp embryos, including regions without nuclei and regions without cytoplasm. Although the first nuclear divisions in Drosophila embryos are synchronous (Foe and Alberts 1983), the nuclei are larger in the anterior half of the homozygous wimp embryo shown in $D$ and at higher magnification in $F$ (arrowhead marks border), suggesting that the posterior half has undergone an extra round of nuclear division. Nuclei appear to migrate into the central yolk region leaving holes in the periphery of the blastoderm cortex (arrow in $E$; and the same embryo at higher magnification in $G$ and $H$ ). For whole embryo sections, anterior is to the left and dorsal is uppermost.
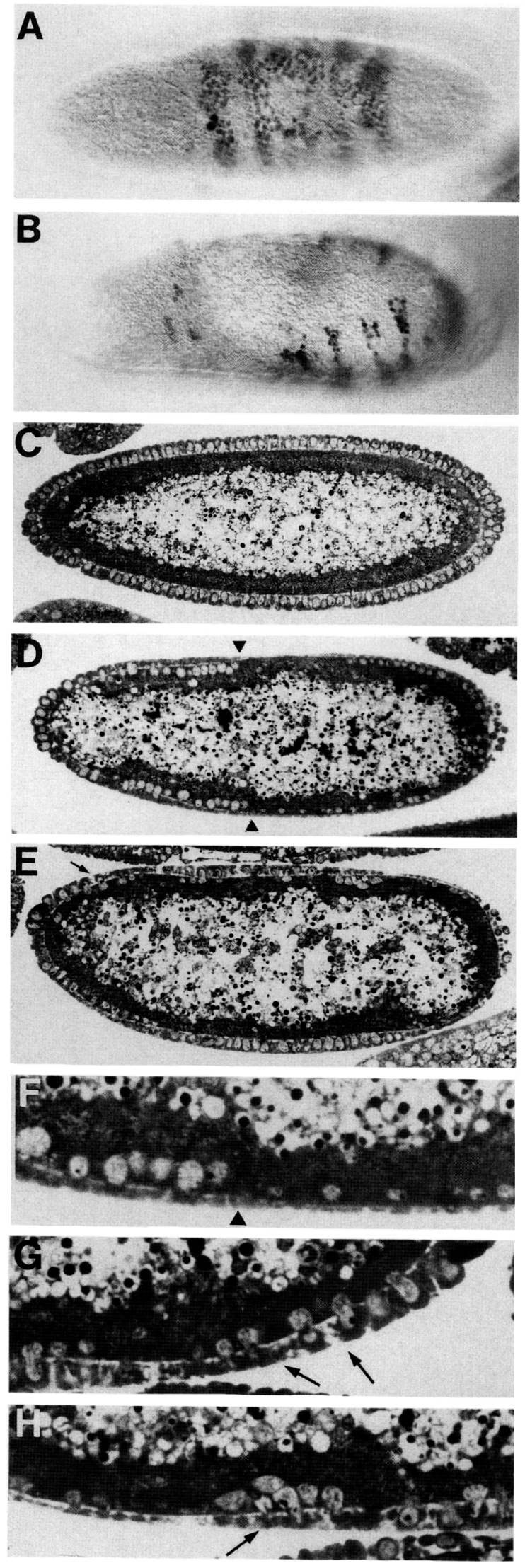
Table 1. Summary of interactions with the wimp maternal effect

\begin{tabular}{|c|c|c|c|}
\hline Class & Interacting & Noninteracting & Reference \\
\hline \multicolumn{3}{|l|}{ Maternal } & 1,2 \\
\hline anterior & exuperantia ${ }^{P / 42}$ & swallow ${ }^{14}$ & 3,4 \\
\hline \multirow[t]{7}{*}{ posterior } & & oskar ${ }^{166}$ & 5 \\
\hline & & pumilio $^{680}$ & 6 \\
\hline & & $\operatorname{nanos}^{L 7}$ & 7 \\
\hline & & vasa $a^{P D 23}$ & 3 \\
\hline & & valois $^{R B 71}$ & 3 \\
\hline & & staufen $^{H L 54}$ & 3 \\
\hline & & tudor ${ }^{\text {WC8 }}$ & 8 \\
\hline terminal & trunk $^{R A 41}$ & torso $^{\text {WK34 }}$ & 3,3 \\
\hline \multirow[t]{7}{*}{ dorsal } & dorsal ${ }^{1}$ & easter ${ }^{1}$ & 9,10 \\
\hline & & snake $e^{073}$ & 10 \\
\hline & & pipe 664 & 10 \\
\hline & & tube $e^{Z 38}$ & 10 \\
\hline & & TOll ${ }^{9 Q R E}$ & 11 \\
\hline & & cappuccino $^{\text {HK3,ci }}$ & 12 \\
\hline & & spire $e^{R P 48}$ & 12 \\
\hline ventral & $\operatorname{cactus}^{A 2}$ & & 3 \\
\hline others & daughterless ${ }^{2}$ & Polycomb $b^{3}$ & 13,23 \\
\hline \multicolumn{4}{|l|}{ Zygotic } \\
\hline dorsal/ & $t w i s t^{I D 96}$ a & zerknüllt $t^{\text {wo }}$ & 14,15 \\
\hline ventral & snaillicios a & decapentaplegic ${ }^{27}$ & 14,14 \\
\hline \multirow{5}{*}{ cardinal } & Krüppel $^{1.2}$ & & \\
\hline & & hunchback ${ }^{\text {PXT15 }}$ & 14,16 \\
\hline & giant $^{Y A}$ & tailless ${ }^{L 1 O}$ & 17,16 \\
\hline & unpaired YC $4.3, Y M 5.5^{-}$ & huckebein ${ }^{2}$ & 17,18 \\
\hline & knirps $^{11 D 48}$ & & 16 \\
\hline \multirow[t]{6}{*}{ pair-rule } & hairy ${ }^{122}$ & sloppypaired $^{7648}$ & 16,14 \\
\hline & even-skipped 1.27 .3 .77 .17 & odd-skipped ${ }^{I I I 136}$ & 14,14 \\
\hline & runt $^{I I / 2}$ & & 17 \\
\hline & fushi tarazu $u^{1) f\left(s_{c} b\right) . w 20}$ & & 16 \\
\hline & paired $d^{I I N 27,2.45 .17 \mathrm{~b}}$ & & 14 \\
\hline & odd-paired $d^{5 H 97 \mathrm{~b}}$ & & 16 \\
\hline \multirow{6}{*}{$\begin{array}{l}\text { segment } \\
\text { polarity }\end{array}$} & & engrailed $^{B}$ & 14 \\
\hline & & wingless & 14 \\
\hline & & patched ${ }^{\text {INIOS }}$ & 14 \\
\hline & & smooth $\mathrm{Q14}$ & 14 \\
\hline & & naked $d^{78 \%}$ & 16 \\
\hline & & gooseberry ${ }^{I I X}$ & 14 \\
\hline \multirow[t]{3}{*}{ homoeotics } & & Ultrabithorax ${ }^{1}$ & 23 \\
\hline & & Polycomb $b^{3}$ & 23 \\
\hline & & $B X-C(D f(3 R) P 9)$ & 23 \\
\hline \multirow{8}{*}{ others } & orthodenticle $\mathrm{YH}^{\mathrm{YH}}$ & empty spiracles ${ }^{71) 99.10 A .37}$ & 17,16 \\
\hline & Sex-lethal ${ }^{\gamma B O}$ & buttonhead ${ }^{H I A}$ & 19,17 \\
\hline & sisterless- $a^{c}$ & string & 20,16 \\
\hline & sisterless-b $\left(s c^{3 \cdot I}\right)^{c}$ & branch $^{\text {IOEt I.3 }}$ & 20,16 \\
\hline & $f t z-1 a c C / F G 2^{d}$ & $R p I I 215^{(t b)}$ & 22,21 \\
\hline & & UPHZ5OT & 22 \\
\hline & & tailup $p^{I I B 29}$ & \\
\hline & & u-shaped $d^{I A 102}$ & \\
\hline
\end{tabular}

${ }^{\mathrm{a}}$ Only $\sim 40 \%$ and $55 \%$ of the expected embryos are embryonic lethal showing a twist or snail cuticular phenotype, respectively.

${ }^{b}$ The gap gene knirps and the pair-rule genes paired and odd-paired do not lead to complete embryonic lethality: $80 \%$ (94/118), 5\% $(5 / 102), 32 \%(14 / 44)$, and $52 \%(41 / 79)$ for $\mathrm{kni}^{11 D 48}$, prd $d^{2.45 .15}, \mathrm{prd}^{I I N 27}$, and opa ${ }^{5 H 97}$, respectively survive to adulthood.

${ }^{c}$ For sisterless- $a$ and sisterless- $b, 39 \%(24 / 62)$ and $84 \%(46 / 55)$ of the progeny are embryonic lethal, respectively. Of the surviving progeny, $85 \%(197 / 232)$ and $67 \%(330 / 491)$ are male, respectively.

$\mathrm{d} f \mathrm{tz}-\mathrm{lacC}$ and $F G 2$ are germ-line transformants carrying a fusion gene with the $\mathrm{ftz}$ promoter driving the expression of $\beta$-galactosidase in a ftz pattern (Hiromi et al. 1985; Hiromi and Gehring 1987).

${ }^{\text {e } U P H Z 50 T ~ i s ~ a ~ g e r m-l i n e ~ t r a n s f o r m a n t ~ w i t h ~ t h e ~} f t z$ upstream enhancer sequences placed in reverse orientation $5^{\prime}$ to a $h s p 70-\beta-g a l$ reporter construct (Hiromi and Gehring 1987).

References: (1) Frohnhöfer and Nüsslein-Volhard (1986); (2) Mohler and Wieschaus (1986); (3) Schüpbach and Wieschaus (1986); (4) Frohnhöfer and Nüsslein-Volhard (1987); (5) Lehmann and Nüsslein-Volhard (1986); (6) Lehmann and Nüsslein-Volhard (1987); (7) Lehmann (1988); (8) Boswell and Mahowald (1985); (9) Nüsslein-Volhard (1979); (10) Anderson and Nüsslein-Volhard (1986); (11) Anderson et al. (1985); (12) Manseau and Schüpbach (1989); (13) Cline (1980); (14) Nüsslein-Volhard et al. (1984); (15) Wakimoto et al. $(1984)_{;}(16)$ Jürgens et al. (1984); (17) Wieschaus et al. (1984); (18) Wiegel et al. (1990); (19) Cline (1986); (20) Cline (1988); (21) Mortin and Lefevre (1981); (22) Hiromi et al. (1985)/Hiromi and Gehring (1987); (23) Lewis (1978). 

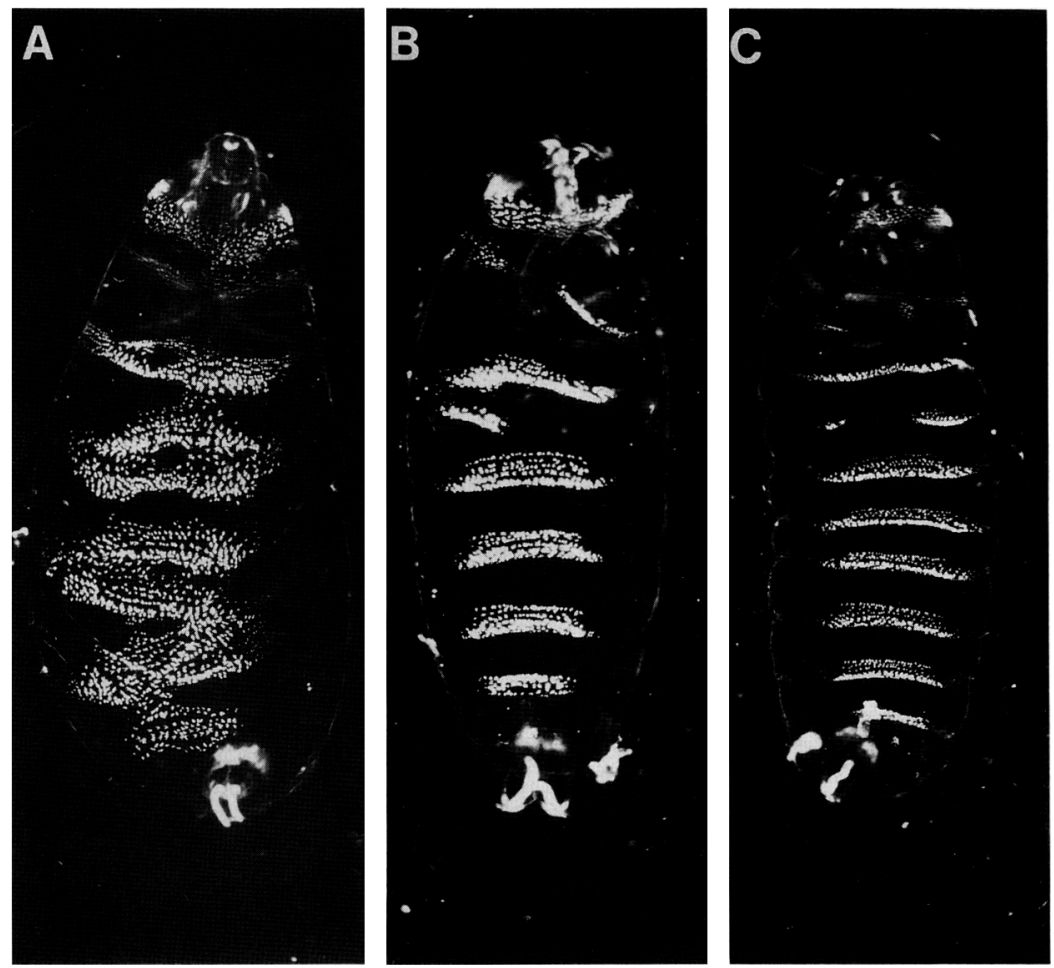

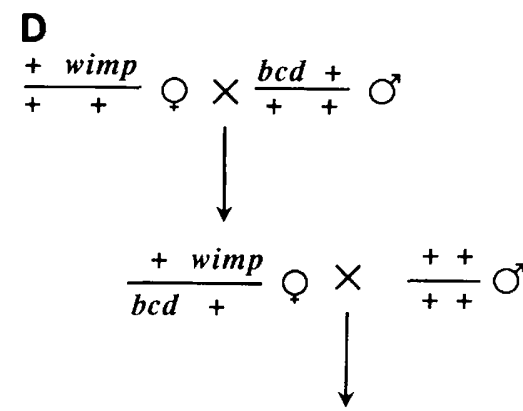

EMBRYONIC LETHAL

Figure 3. Interaction of the wimp maternal effect with maternally and zygotically active genes. $(A)$ Cuticle phenotype of a heterozygous $h$ larva derived from a wimp/ + mother showing pair-wise segmental fusions characteristic of intermediate homozygous $h$ larvae. $|B|$ Cuticle phenotype of a heterozygous $K_{r}$ embryo derived from a wimp/+ mother showing segmental deletions characteristic of homozygous $K r$ larvae. $(C, D)$ Interaction of the maternal gene $b c d$ with the wimp maternal effect. All embryos derived from mothers transheterozygous for the maternal gene $b c d$ and wimp do not survive $|D|$ and show defects in the anterior pattern characteristic of intermediate $b c d$ phenotypes $(C)$. Anterior is uppermost.

tern is affected, the level of expression is not affected /cf. Figs. $4 \mathrm{G}, \mathrm{H}$ with $5 \mathrm{M}, \mathrm{N})$.

\section{wimp affects the transcription of interacting genes}

That wimp affects the transcription of interacting genes is confirmed by in situ analysis of $f t z$ transcription, comparing wimp embryos with oskar (osk) embryos that can be recognized by their lack of pole cells /see Materials and methods; Lehmann and Nüsslein-Volhard 1986; Driever and Nüsslein-Volhard 1988b). [The $f t z$ pattern, but not level, is altered in osk embryos (Lehmann 1988).) Figure 5, E-J, shows that levels of $f t z$ transcripts are clearly reduced in wimp embryos, indicating that the reduced protein levels result from a primary defect in transcription. $h$ transcripts are similarly lowered in wimp embryos (not shown). As wimp affects both maternal and zygotic genes, reduced transcript levels seem unlikely to be due to lowered mRNA stability. Rather, it appears that wimp may diminish the efficiency of transcription.

Transcription of noninteracting genes is unaffected in wimp embryos

There are two alternative explanations for selective interactions with the wimp maternal effect. First, the dis- tinction could reflect different threshold requirements for development: All transcript levels are reduced in wimp embryos, but there would be no apparent developmental consequences for noninteracting genes. Alternatively, noninteracting loci are wimp independent and retain normal transcript levels. We have confirmed the latter explanation by showing that expression levels of several noninteracting genes are the same in wimp and wild-type embryos. Figure $5, \mathrm{~K}-\mathrm{P}$, shows that $h b$, zerknüllt (zen), and en protein levels do not differ among embryos of wimp heterozygous mothers and osk females. Indeed, Figure 4, G and $\mathrm{H}$, shows that en levels (though not their pattern) are normal in wimp/ftz embryos in which $f t z$ expression is reduced to essentially undetectable levels. Even-numbered en stripes correspond to the anterior margins of $f t z$ expression (Lawrence et al. 1987; Carroll et al. 1988), so individual cells can express reduced $f t z$ and normal en levels (Figs. $4 \mathrm{~B}$ and $5 \mathrm{~N}$ ). We also find that transcript levels of torso (tor) and UPHZ5OT (see Table 1) are unaffected (not shown). Thus, transcription of many, if not all, noninteracting loci is wimp insensitive.

wimp is allelic to an RNA polymerase subunit

wimp maps to position $54 \mathrm{cM}$ on chromosome $3 \mathrm{R}$, within the region duplicated in $D p(3 R) k a r^{51}$ (86D-90F) 

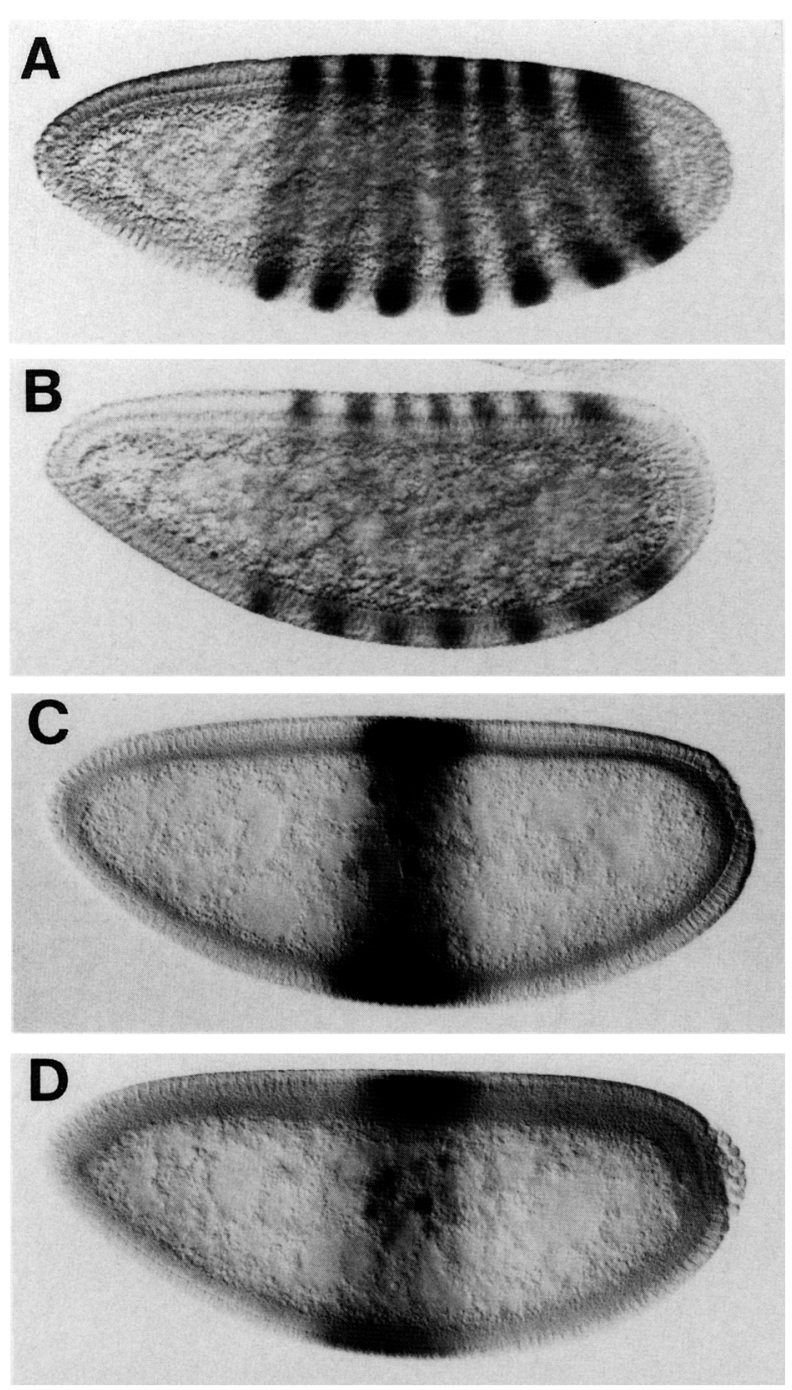
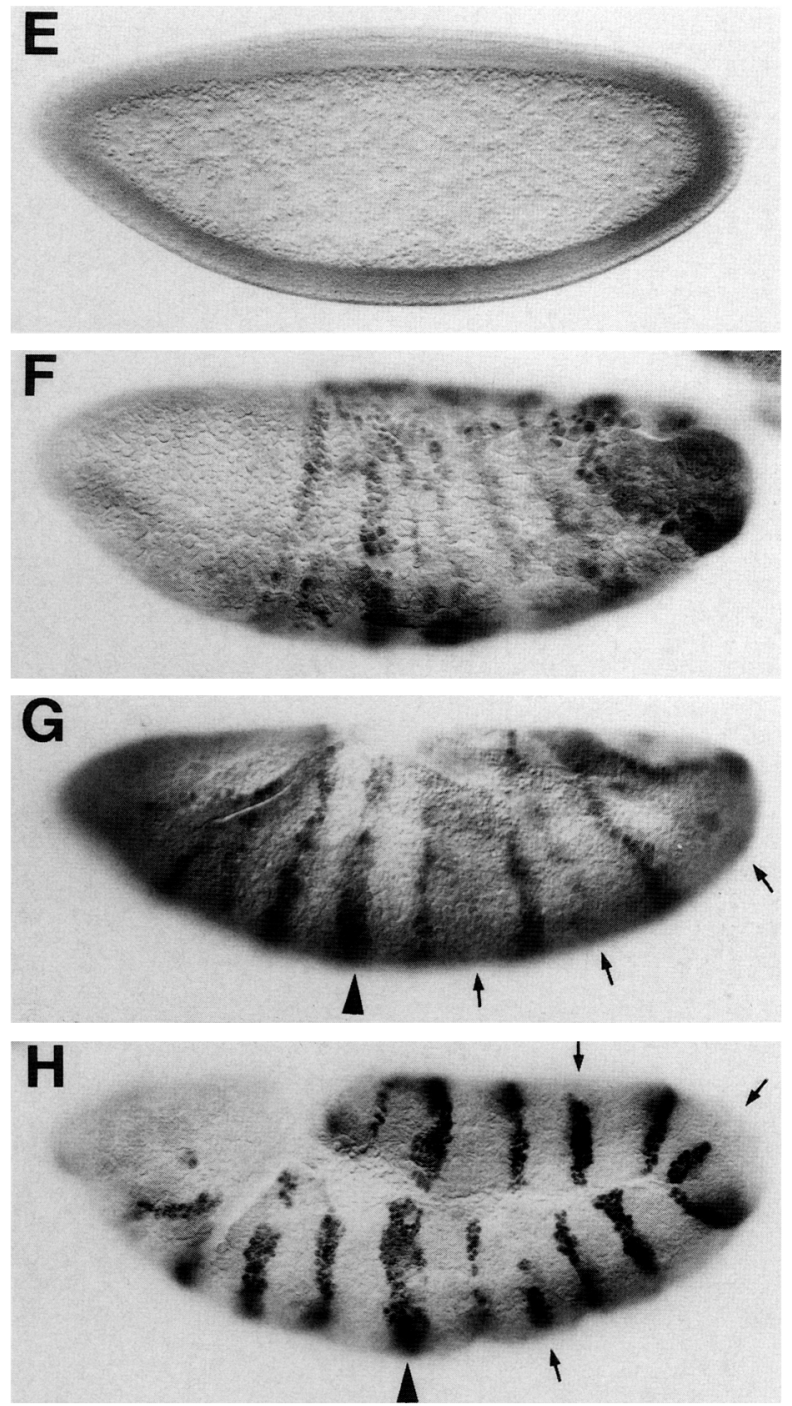

Figure 4. Protein levels are reduced in wimp embryos. $f t z$ protein expression is reduced in embryos from wimp/ + mothers $(B)$ compared to wild-type $(A)$ embryos. Similarly, the $K r$ protein levels are reduced in wimp $(D)$ compared with wild-type $(C)$ embryos. To standardize the staining, these embryos have been processed in parallel and stained and photographed identically. $(E-F)$ Heterozygous $f t z$ progeny from a wimp/ + mother stained with anti-ftz antibodies. The level of protein expression is undetectable for most embryos $(E)$, consistent with their cuticle patterns. Occasional embryos show very weak and disorganized $f t z$ protein expression $(F)$. (The staining intensity of this embryo has been photographically enhanced to show the disorganized pattern.) $(G, H)$ Reduced $f t z$ expression in homozygous $f t z$ embryos is associated with the lack or disruption of the even-numbered en stripes (Howard and Ingham 1986). As expected, the heterozygous $\mathrm{ftz}$ progeny from a wimp/+ mother stained with anti-en antibodies shows an altered en pattern. Such embryos show a broadened fourth stripe (arrowhead) and reduction or absence of other even-numbered stripes (arrows). For all embryos, anterior is to the left and dorsal is uppermost.

(see Materials and methods; P. Ingham, unpubl.). More precise mapping shows that the recessive lethality and the maternal effect colocalize, indicating that both are due to the same mutation (Fig. 6A; Materials and methods). The wimp locus is deleted in $D f(3 R)$ red $^{P 1}$ but retained in $D f(3 R)$ red $^{P 93}$, mapping it to $88 \mathrm{~B} 1,2$.

Chromosomal deficiencies uncovering wimp do not interact with segmentation gene mutations (see Materials and methods), suggesting that wimp encodes an altered function. Moreover, homozygous wimp ${ }^{-}$deficiencies lack the segment fusions and cellularization defects characteristic of wimp/wimp embryos (Fig. 6C). To examine a null wimp allele, we isolated a revertant, wimp$R Q$, that no longer shows maternal interactions (see Materials and methods). This mutation fails to complement the zygotic lethality of the original wimp allele and maps to the same chromosomal region as wimp but no longer interacts with $h$ and other segmentation genes. Cellularization and segmentation are normal in homozygous wimpRQ embryos (Fig. 6D) and are not affected in wim$p R Q /$ wimp embryos unless derived from wimp/ + mothers (see Materials and methods). 

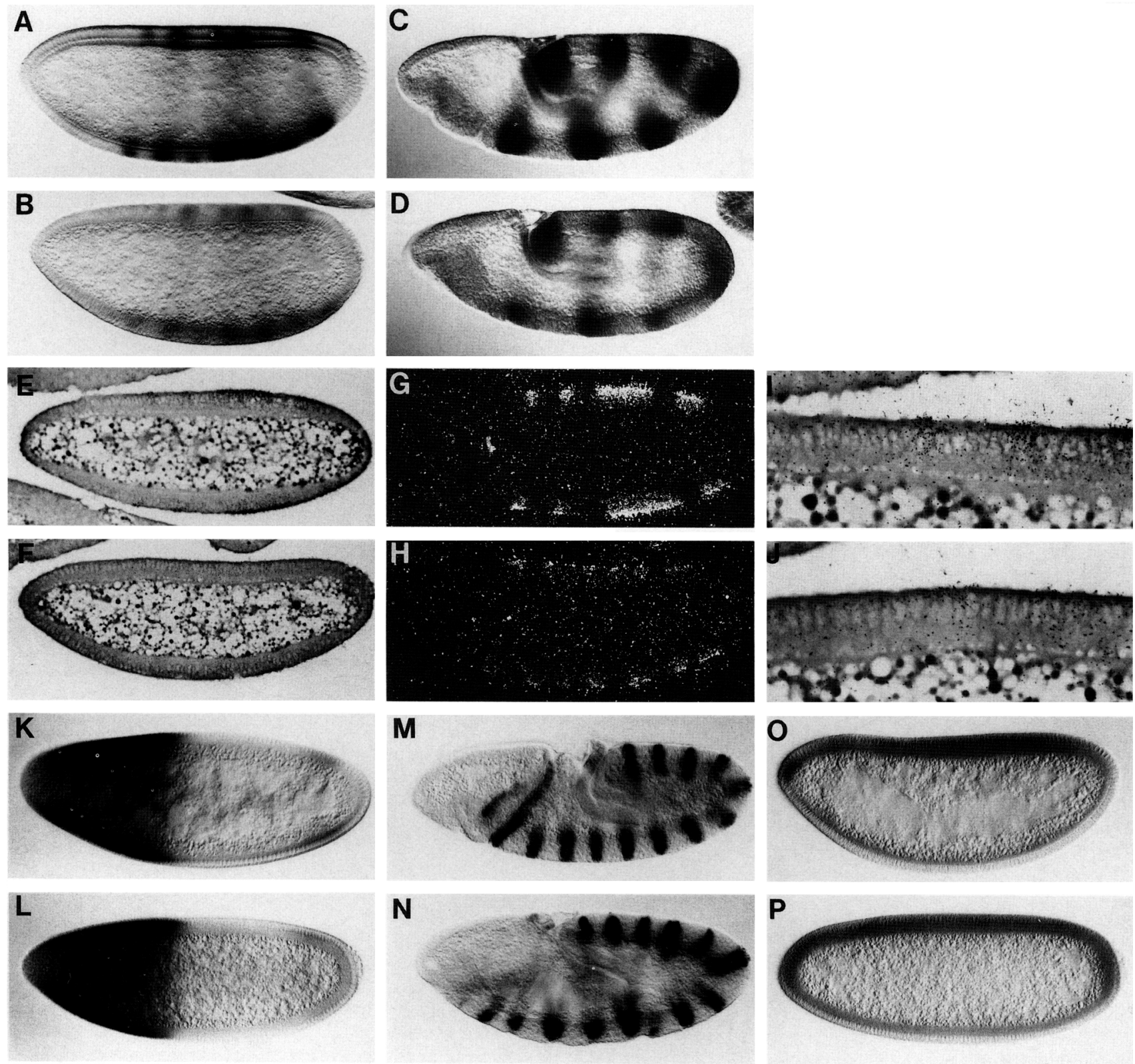

Figure 5. wimp aftects transcription of interacting but not noninteracting genes. $\beta$-gal protein expression is reduced for a $f t z-l a c Z$ hybrid gene in blastoderm or germ band-extended embryos derived from wimp $(B, D)$ compared with wild-type mothers $(A, C)$, suggesting that wimp acts at the level of transcription. In situ hybridization has confirmed that $f t z$ transcription is substantially reduced in similarly staged embryos derived from heterozygous wimp $(F, H, I)$ compared with homozygous osk $(E, G, I)$ females. Embryos derived from homozygous osk females have wild-type levels but altered patterns of $f t z$ expression (Lehmann and Nüsslein-Volhard 1986; Driever and Nüsslein-Volhard 1988b). $\{E, F\rangle$ Bright field; $\{G, H\rangle$ dark field. Higher magnification of the ventral cortex surrounding the stripe 1 region of the sections in $E$ and $F$ shows that the embryos are of similar staging. The level of protein expression does not differ between wild-type (control) and wimp embryos stained for protein from the noninteracting genes $h b(K, L)$, en $(M, N)$, and zen $(O, P)$, respectively. The control embryos for the $h b$ and zen staining were from homozygous osk mothers and were mixed with wimp embryos during fixation and staining. For all embryos, anterior is to the left and dorsal is uppermost.

wimp maps to a region previously cloned in a phage/ cosmid "walk" (R.L. Kelley, pers. comm.; S.M. Parkhurst, unpubl.|. Despite wimpRQ being a $\gamma$-ray-induced revertant, we were unable to detect differences in chromosomal organization between wimp, wimpRQ and the parental stock using genomic Southern blots (data not shown). We therefore localized the wimp gene by cosmid rescue (see Materials and methods). Two cosmids, 15 and 92 , rescue flies homozygous for wimp and wimpRQ (Fig. 6A). These cosmids also rescue the maternal effect, pre- 
A
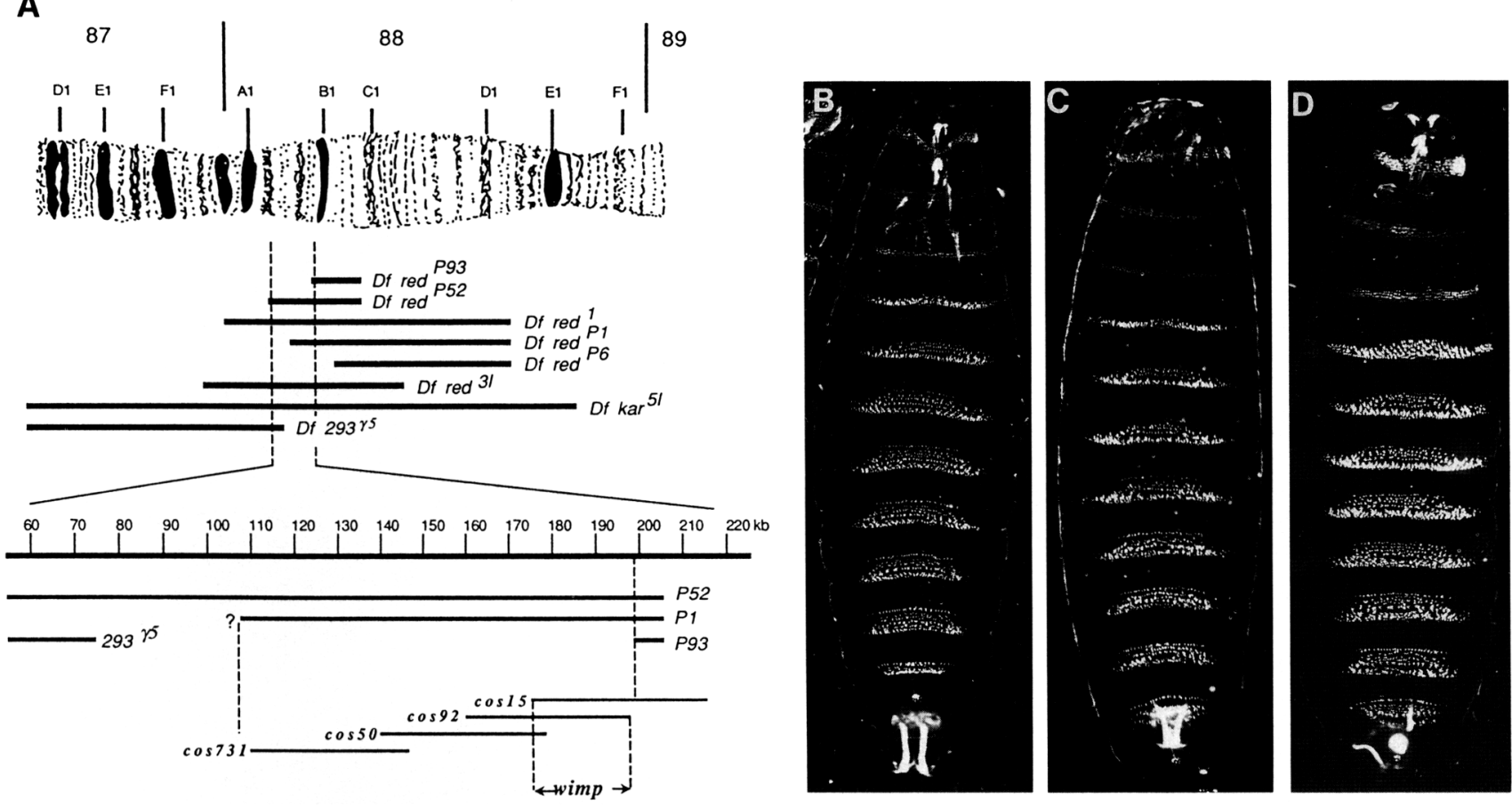

Figure 6. Genetic and molecular localization of wimp and wimpRQ. (A) Diagram of the 87-89 region of chromosome 3. The horizontal solid lines indicate the genetic material deleted in each of the chromosomal deficiencies shown. The molecular extent of the small genetic region containing wimp and wimpRQ defined by complementation analysis with the deficiencies is shown, indicating the four overlapping cosmids that were used in the rescue experiments and the region of $\sim 25-\mathrm{kb}$ overlap that rescues this locus. The end points of the deficiencies have been mapped to particular restriction fragments, and their positions on the molecular map are approximate. The cuticular phenotype of wild-type $(B)$; a deficiency $\left(D f(3 R)_{\text {red }}{ }^{P 1} / D f(3 R)_{\text {red }}{ }^{31}\right)$ for the wimp locus $(C)$; and the homozygous phenotype of the wimpRQ revertant $\langle D|$ are shown. The deficiency for the region has normal denticle patterns with the exception of defects in the mouth parts and a transformation of the denticles in the eighth abdominal segment characteristic of the trithorax mutation contained within the deleted region (Ingham 1983). The wimpRQ revertant phenotype (D) resembles the deficiency phenotype $(C)$ with normal denticle patterns except for defects in the mouth parts rather than the homozygous wimp phenotype (Fig. $1 \mathrm{~B}, \mathrm{C}$. Anterior is uppermost in all cases.

sumably by providing an extra wild-type gene copy. Thus, wimp must map within the $\sim 25-\mathrm{kb}$ region of overlap between the two cosmids (Fig. 6A).

This interval includes two lethal complementation groups defined by saturation mutagenesis (M. A. Mortin, pers. comm.). Crosses to alleles of these loci show that wimp and wimpRQ fail to complement the zygotic lethality of mutations $\mathrm{A} 5, \mathrm{Z3}$, and $\mathrm{Z} 24$, alleles of the second largest subunit of RNA polymerase II, RpII140 (Mortin 1990; B. Hamilton, M.A. Mortin and A. Greenleaf, in prep.). The effects of wimp on transcription appear to be due to an altered RNA polymerase II subunit, and the precise nomenclature for the original mutation and its revertant should be $1(3)$ RpIII $140^{\text {wimp }}$ and l(3)RpII140 ${ }^{\text {wimpRQ }}$.

\section{Altered bcd levels in wimp embryos do not affect the} fate map

Driever and Nüsslein-Volhard (1988a,b) have shown that $b c d$ behaves as an anterior morphogen, with different levels of $b c d$ protein defining different anteroposterior positions. Surprisingly, we noticed that wimp reduces $b c d$ levels without appearing to alter the embryonic fate map. We defined the extent of bcd reduction by comparing wimp embryos to those with one or two maternal $b c d^{+}$copies (see Materials and methods).

Figure 7, A-C, shows that the intensity of $b c d$ staining in wimp embryos is comparable to that of embryos from $b c d$ heterozygous mothers, that is, $\sim 50 \%$ of wild type (Driever and Nüsslein-Volhard 1988b). Nevertheless, there is no corresponding shift in the blastoderm fate map, as judged by the positions of eve (Fig. 7D-G) and ftz stripes 1 (not shown). Reducing maternal bcd dosage by $50 \%$ shifts the anterior margin of eve stripe 1 by $6 \%$ of egg length (Table 2; cf. Driever and Nüsslein-Volhard 1988b), while stripe positions are unchanged in wimp embryos. We suggest that the effects of reduced $b c d$ levels in wimp embryos are modulated by equivalent reductions in other factor(s) (see Discussion).

\section{A powerful genetic screen for novel loci affecting early development}

Although the majority of loci that cause cuticular pattern defects have been identified in previous screens 

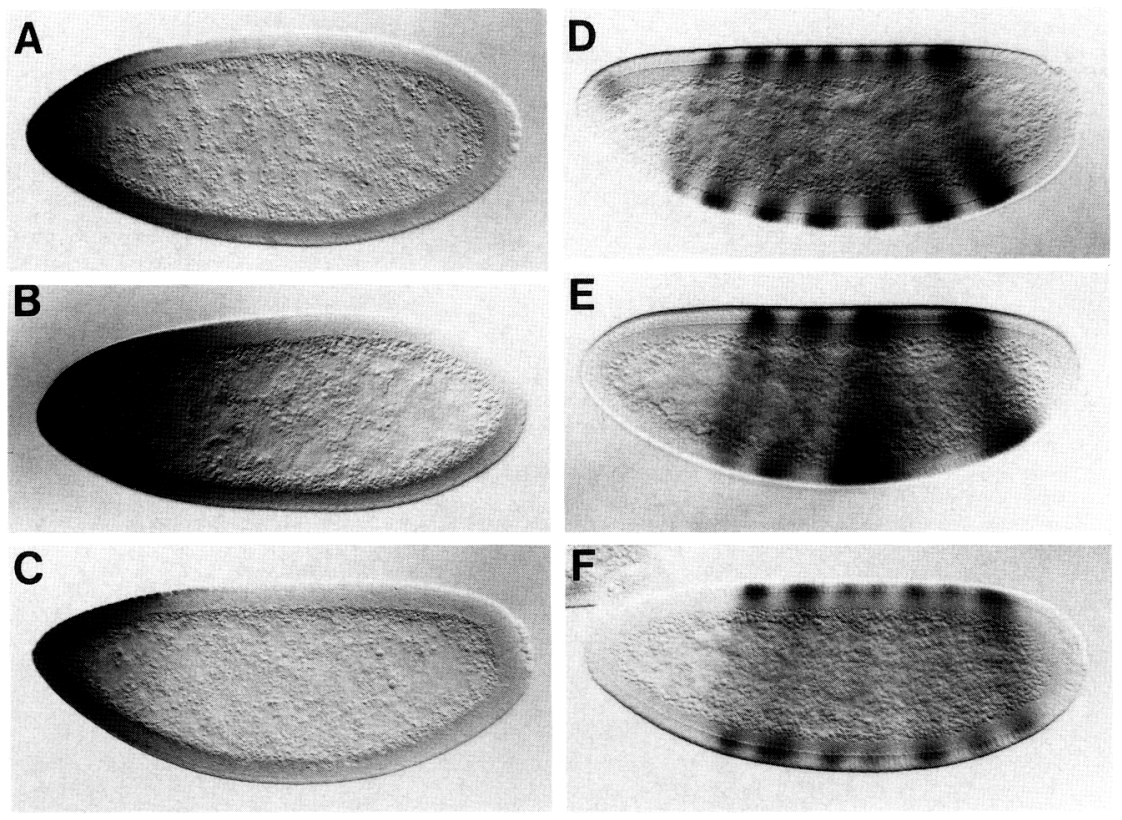

Figure 7. $b c d$ levels and the embryonic fate map in wimp embryos. $(A, B \mid b c d$ protein expression in embryos from females with one or two copies of $b c d^{+}$, respectively. These two classes have been processed together to control for the fixing/staining artifacts, the latter class being distinguished by the lack of pole cells due to the homozygous maternal mutation osk. $|C|$ bcd protein expression in embryos (from wimp/+ females) contain two wild-type copies of $b c d^{+}$. Despite the presence of two wild-type copies of $b c d^{+}$, the intensity of anti-bcd staining is reduced $>50 \%$, comparable to embryos with one wild-type copy of $b c d^{+}$(Driever and Nüsslein-Volhard 1988b). These embryos were also processed with embryos derived from homozygous osk mothers for an internal control. All embryos were photographed and printed under the same conditions. $\left\{D, E \mid\right.$ Expression pattern of eve in embryos from females with one or two copies of bcd ${ }^{*}$, respectively. $(F)$ eve expression in embryos from wimp/ + females that contain two wild-type copies of bcd ${ }^{*}$. $(G)$ Comparison of the ventral surface of the embryos shown in $D-F$ showing the anterior shift in embryos with one copy of $b c d^{+}$(upper). The arrowheads mark the position of $e v e$ stripe 1 in wild-type (two copies of $b c d^{+}$) embryos (middle). Reduced bcd expression in wimp embryos does not shift the position of eve stripe 1 (lower). For all embryos, anterior is to the left and dorsal is uppermost.

(Nüsslein-Volhard and Wieschaus 1980; Jürgens et al. 1984; Nüsslein-Volhard et al. 1984; Wieschaus et al. 1984; Schüpbach and Wieschaus 1986), several classes of mutations would have been missed in such experiments. These would include duplicated loci that encode related products, zygotic loci with significant maternal contributions, and mutations that cause early embryonic lethality before cuticle is laid down. Indeed, wimp itself is an example of a general transcription factor whose effects are not specific to segmentation.

Table 2. The embryonic fate map in wimp embryos

\begin{tabular}{|c|c|c|c|c|c|}
\hline \multirow{2}{*}{$\begin{array}{l}\text { Maternal } \\
\text { genotype }\end{array}$} & \multirow{2}{*}{$\begin{array}{l}\text { Copies } \\
b c d^{+}\end{array}$} & \multicolumn{2}{|c|}{$f t z$} & \multicolumn{2}{|c|}{ eve } \\
\hline & & stripe 1 & stripe 7 & stripe 1 & stripe 7 \\
\hline$\overline{b c d^{E 1} /+}$ & 1 & - & - & $76.2 \pm 1.4$ & $24.3 \pm 2.3$ \\
\hline osk/osk & 2 & 66 & 13 & $70.4 \pm 1.8$ & $21.9 \pm 2.9$ \\
\hline wimp/+ & 2 & 66 & 12 & $70.2 \pm 1.6$ & $21.0 \pm 2.8$ \\
\hline
\end{tabular}

Embryos were measured in percent egg length, where $0 \%$ is the posterior end. In all cases, 15 stage 14 embryos were measured.
We have identified such novel loci by screening for maternal and zygotic mutations that interact with wimp. The strategy for isolating zygotic loci is shown in Figure 8A: Induction of an interacting mutation causes lethality in heterozygous progeny of wimp mothers. The zygotic screen also recovers second-site enhancers of the wimp mutation that are not dependent on the wimp maternal effect (see legend to Fig. 8). A slightly modified screen allows the recovery of maternally interacting mutations: mothers transheterozygous for wimp and novel mutations lay eggs whose development is affected (Fig. $8 \mathrm{E})$.

In a preliminary experiment, we recovered seven zygotic and four maternal mutations from 744 and 589 ethylmethane sulfonate (EMS)-mutagenized chromosomes, respectively. All proved to be recessive lethals whose phenotypes (see below) resembled those seen in combination with wimp. Thus, wimp renders many recessive mutations pseudodominant, greatly simplifying their recovery and analysis. We are currently determining whether any of these mutations represent previously characterized loci. 
The newly induced mutations show a variety of phenotypes. Figure 8 presents cuticular preparations of embryos derived from three zygotic $(\mathrm{B}-\mathrm{D})$ and three maternal $(\mathrm{F}-\mathrm{H})$ mutations. All maternal mutations are recessive zygotic lethals, indicating that they are required both maternally and zygotically. One mutation, 8.14, shows similar maternal and zygotic phenotypes: knirpslike fusions of abdominal segments Al-7 (Fig. 8F-H). The maternal phenotype is variable (cf. Fig. $8 \mathrm{H}, \mathrm{I}$ ), but the homozygous zygotic phenotype is consistent (Fig. 8J). Mutation 8.14 maps to chromosome 2 (unpubl.) and appears to represent a novel segmentation gene. We expect this and future mutations to encode novel factors whose activities are crucial for early development.

\section{Discussion}

Specificity of wimp interactions reflects differential interactions with RNA polymerase

Deletion mapping and complementation analysis place wimp in the RpII140 complementation group, the second largest subunit of RNA polymerase II (Fig. 6A; Mortin 1990; B. Hamilton, M.A. Mortin, and A. Greenleaf, in prep.). The strong homozygous wimp phenotype and the lack of interaction of chromosomal deletions for the locus indicate that the wimp allele encodes an altered $R p I I 140$ protein, rather than a complete loss of subunit function. This is confirmed by the wimpRQ revertant that no longer interacts with early genes and that has normal cellularization and segmentation phenotypes.

We have shown that expression of all interacting genes tested is reduced in wimp embryos (i.e., embryos from wimp/ + mothers), apparently due to reduced transcript levels (Figs. 4, 5, and 7). Presumably, the altered RNA polymerase subunit reduces transcription of affected loci so that a single wild-type copy of the interacting gene being tested no longer supports normal development. We suggest that the locus selectivity of wimp reflects promoter-specific mechanisms of transcriptional activation. This is consistent with the proposal that different transcription factors recognize different faces of the large multisubunit RNA polymerase II (Mortin 1990). Several zygotic suppressors of mutations in the large subunit of RNA polymerase II are allele-specific, indicating that each compensates for a different perturbation in polymerase function (Mortin 1990). The wimp mutation would alter one face of the polymerase, only perturbing interactions with factors recognizing that face. Alternatively, the RpII140 subunit may not be required for all transcription complexes.

An individual locus will be susceptible to wimp if it requires the activity of factor(s) using that subunit or the altered face. Noninteracting genes are not distinguished by dose sensitivity. Indeed, all of the noninteracting genes that we have tested ( $h b$, tor, zen, en, UPHZ5OT) show normal levels of expression in embryos from heterozygous wimp mothers, suggesting that they utilize different transcription factors from interacting loci. Of course, there may be wimp-sensitive genes that do not interact phenotypically, genes whose transcription is affected but that retain sufficient expression for normal development.

All of the interacting genes that we have identified act during or before the blastoderm stage. This is not because wild-type polymerase function is supplemented by zygotic $R p I I 140$ protein made during the late blastoderm stage. Depressed $f t z$ expression in wimp embryos persists throughout gastrulation and into germ-band extension: thus, individual cells can express en normally, while $f t z$ expression is depressed (Figs. $4 \mathrm{~B}$ and $5 \mathrm{~N}$ ). In addition, wimp/wimp embryos, completely lacking zygotic wild-type RpII140, express normal levels of en, although the domains are distorted by cellularization defects (Fig. 2B).

\section{Gene-balance and positional cues in the Drosophila embryo}

There is considerable evidence that the $b c d$ protein gradient acts as an anterior morphogen, defining position on the embryonic fate map by organizing spatial expression of zygotic segmentation genes (Frohnhöfer and NüssleinVolhard 1986; Driever and Nüsslein-Volhard 1988a,b, 1989; Tautz 1988; Driever et al. 1989, 1990; Struhl et al. 1989|. Manipulating gene dosage to reduce $b c d$ concentrations shifts anterior anlagen posteriorly; increasing $b c d$ concentrations anteriorizes cell fates (Driever and Nüsslein-Volhard 1988b). Nevertheless, reduced bcd expression in wimp embryos is not accompanied by an anterior displacement of the fate map (Fig. 7D-G; Table 2). $h b$ expression appears unaffected in wimp embryos (Fig. $5 \mathrm{~K}, \mathrm{~L}$ ), despite the strong evidence that $b c d$ acts directly in activating anterior $h b$ transcription (Driever et al. 1989; Struhl et al. 1989).

We conclude that reduced $b c d$ levels in wimp embryos must be accompanied by compensatory changes in the expression of other genes, that is, that anteroposterior position is sensed through a balance of factors, rather than the absolute $b c d$ concentration. The fate of an anterior cell would depend on the balance in concentrations between the bcd morphogen and other wimp-sensitive factors. The latter may be generalized, probably maternal, transcription factors that themselves need not convey spatial information.

Similar considerations must apply to establishing dorsoventral position and to pair-rule striping. Dorsoventral fate depends on a dorsoventral gradient of nuclear $\mathrm{dl}$ protein (Steward et al. 1988; Roth et al. 1989; Rushlow et al. 1989; Steward 1989). The phenotypic interaction between wimp and $d l$ (Table 1) suggests that $d l$ protein levels are reduced in wimp embryos. There is no evidence of disrupted dorsoventral pattern in wimp embryos, despite $d l$ being haplo-insufficient (Nüsslein-Volhard et al. 1980). We presume that dorsoventral pattern is measured by comparing levels of $d l$ morphogen to that of other factors.

The unaltered fate map in wimp embryos also argues against pair-rule striping being regulated by absolute concentrations of gap proteins or by ratios between dif- 


\section{Parkhurst and Ish-Horowicz}

A

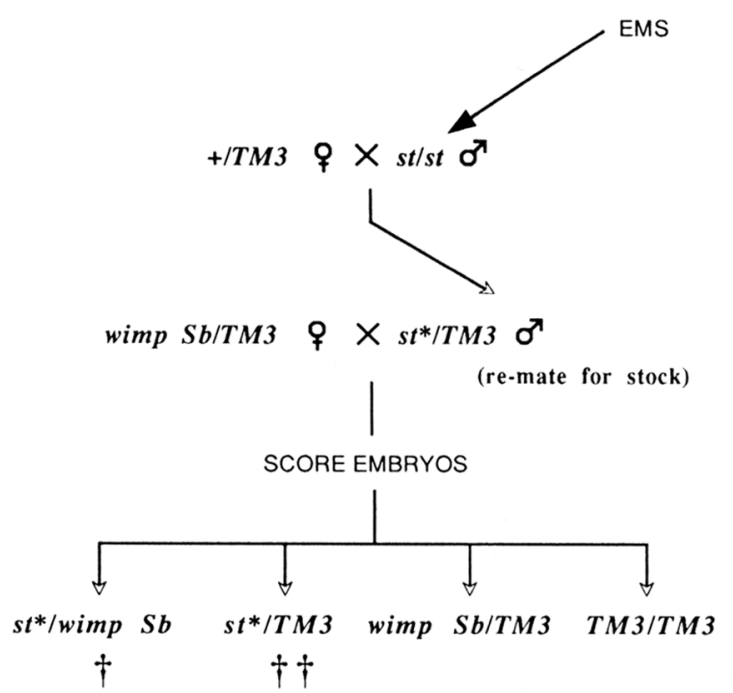

E

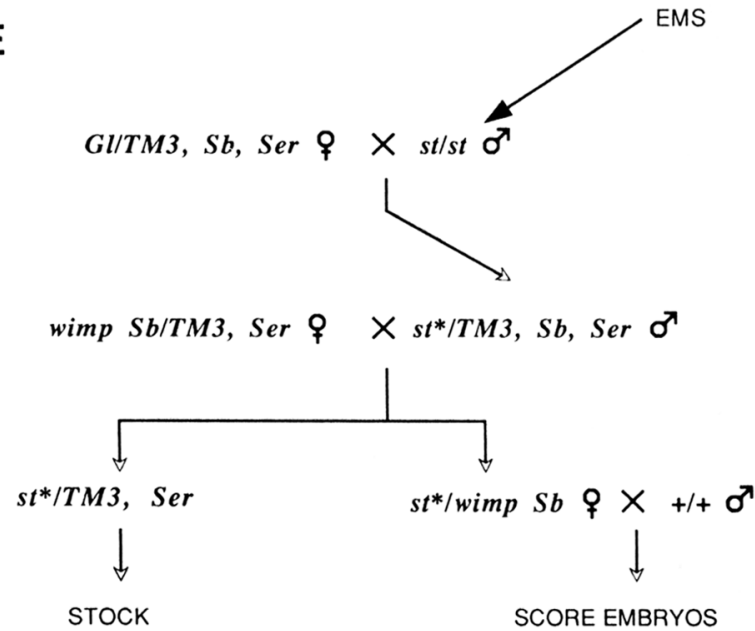

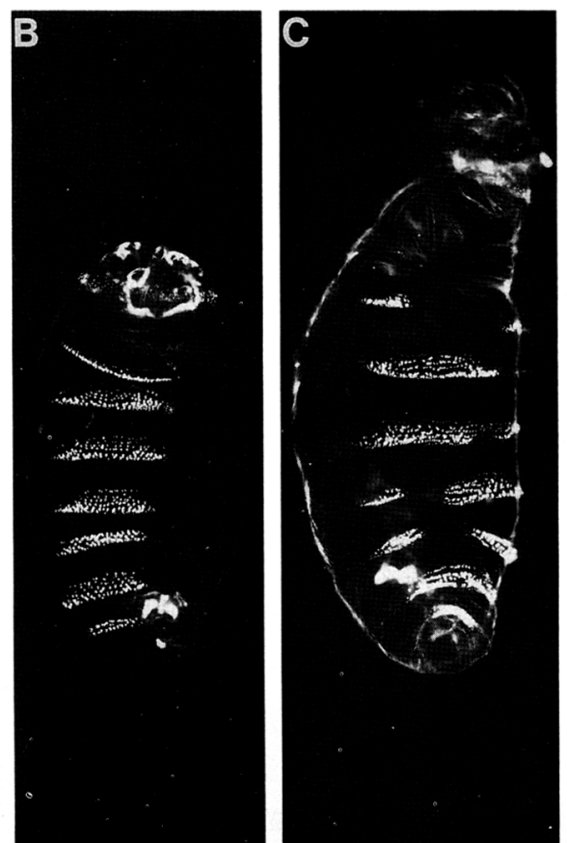
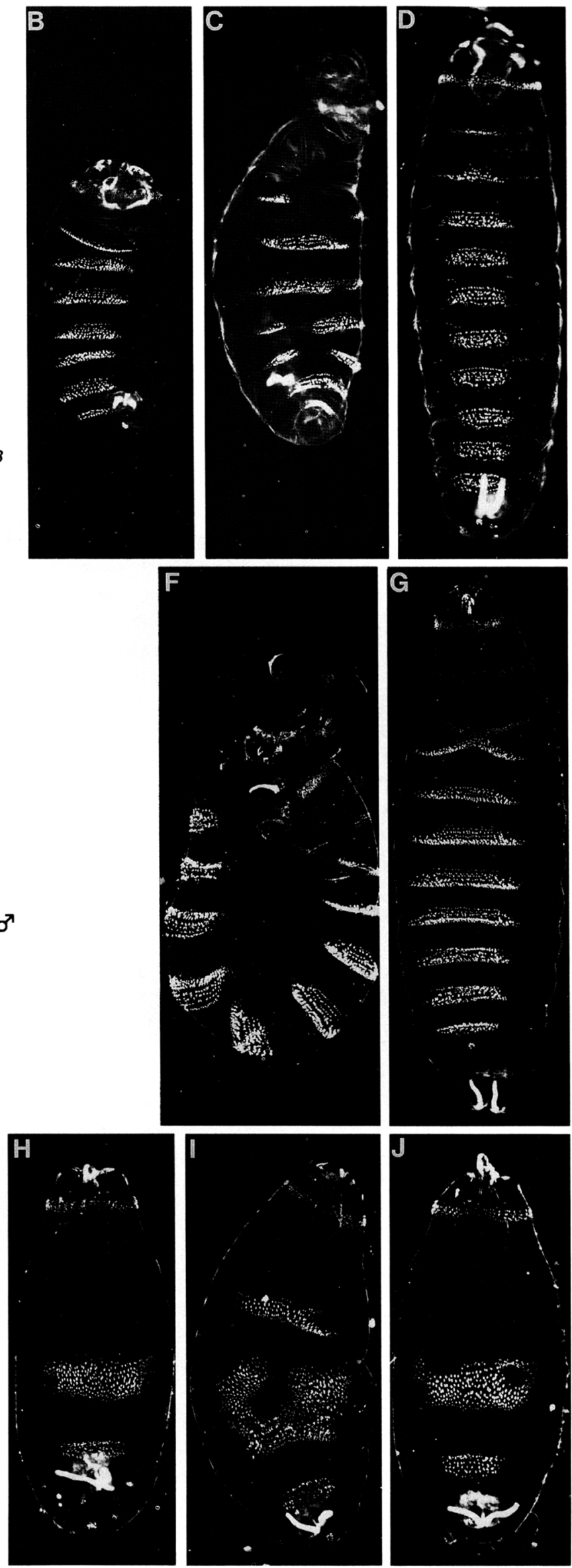

Figure 8. (See facing page for legend.) 
ferent gap proteins. $f t z$ and eve stripes are compressed in $\mathrm{Kr} /+$ embryos (Carroll and Scott 1986; Frasch and Levine 1987), but the reduced $K r$ levels in wimp embryos does not affect the positions of pair-rule stripes (Figs. $4 \mathrm{C}, \mathrm{D}$ and $7 \mathrm{E}, \mathrm{F})$. This indicates that reduced expression of other factors compensates for the reduced $K r$ levels in wimp embryos.

In retrospect, such gene-balance models are not particularly surprising, given the wide variety of transcription factors and their overlapping binding specificities (see Levine and Hoey 1988; Mitchell and Tiian 1989; Hayashi and Scott 1990). Apparently unrelated factors bind to similar DNA sites, indicating that binding by a particular factor will be modulated by potential competitors. Different homeo box proteins can bind the same DNA sequences, and their effects on transcription depend on other coexpressed competitors JJaynes and O'Farrell 1988; Han et al. 1989). Similarly, transcription factors that act as heterodimers (e.g., fos/iun, da/AS-CT4) will be susceptible to competition that affects either member of the protein dimer (Halazonetis et al. 1988; Kouzarides and Ziff 1988; Nakabeppu et al. 1988; Murre et al. 1989; Parkhurst et al. 1990).

\section{wimp and transregulators of early genes}

Most mutations in Drosophila are recessive, requiring that they be studied in homozygous individuals. wimp appears to render many such mutations pseudodominant, greatly simplifying their identification and analysis. Thus, mutational screens for loci that interact with wimp are considerably faster and easier than conventional schemes. We have already identified an apparently novel mutation affecting posterior pattern (see Results), and we recovered mutations that are required both maternally and zygotically, which can be missed in conventional screens because of recessive lethality /see Perrimon et al. 1984). The genes against which $b c d$ levels are measured may fall into this class.

Similarly powerful screens may be necessary to isolate mutations that affect the general transcriptional machinery. The allele specificity shown by second-site suppressors of RNA polymerase II mutations (Mortin 1990) indicates that alternative screens will identify different but overlapping classes of transcriptional regulators. Tricoire (1988) has identified five regions on the X chromosome that interact maternally with the segmentation genes $K r, h b$, or $h$. These also may represent loci encoding polymerase components or other proteins that interact with polymerase.

Null alleles of the wimp locus were not recovered in previous screens for segmentation genes, presumably because the maternal $R p I I 140$ normally deposited into the egg is sufficient to satisfy early transcriptional requirements. Indeed, similar maternal contributions would suppress early zygotic phenotypes from most of the general transcription factors required for early gene expression. Many mammalian transcription factors (e.g., jun, CTF) appear to be encoded as families of related factors that would be refractory to conventional genetic screening (Nakabeppu et al. 1988; Santoro et al. 1988). Such factors may be detectable in the maternal wimp screen, even if they are genetically or functionally redundant, as it sensitizes the embryo to otherwise minor alterations of gene dosage.

wimp will also be useful in studying other early developmental events, including sex determination and blastoderm nuclear division and cellularization. The wide range of loci that are sensitive to wimp means that identifying the affected process will require detailed phenotypic and molecular analysis of mutant embryos. Inducing such mutations by hybrid dysgenesis should allow their immediate molecular cloning and characterization (O'Kane and Gehring 1987; Cooley et al. 1988).

\section{Materials and methods}

Fly stocks

Flies were cultured on yeast/maize meal/molasses/malt extract/agar medium at $25^{\circ} \mathrm{C}$ unless otherwise stated. The allele designation of segmentation genes used is listed in Table 1. wimp was originally designated $h^{9 N 53}$; its full name is now I(3)RpII140 wimp. It was induced on a rucuca (ru h th st cu sr $e^{s}$ ca) chromosome. Most experiments used a recombinant chromosome where these markers have been replaced by the dominant marker Stubble $(S b)$. The official designation of the wimp revertant is $1(3) R p I 1140^{\text {wimpRQ}}$. The deficiencies shown in Figure 6 have been described elsewhere (Lindsley and Zimm 1987; Parkhurst et al. 1988).

\section{Embryo analysis}

Embryos were prepared and analyzed as described by Wieschaus and Nüsslein-Volhard (1986). Antibody staining was performed essentially as described previously by Macdonald and Struhl

Figure 8. Genetic screens for mutations interacting with the wimp maternal effect. The detail shown is for recovering mutations on the third chromosome. (A) Strategy to recover zygotically interacting mutations. Males with genetically marked chromosomes (scarlet $(s t)]$ are mutagenized and outcrossed to balanced (TM3) females. Resulting males, carrying a putative mutation (st ${ }^{\circ} / \mathrm{TM} 3$ ), are then mated to wimp $S b / T M 3$ females. For induced mutations that interact with the wimp maternal effect, the two classes of progeny marked with single and double daggers do not survive. For mutations that interact with zygotically contributed wimp product (i.e., second-site noncomplementing locil, only the class marked with a single dagger dies. $(B-D)$ Homozygous cuticle phenotypes of three zygotically interacting mutations isolated in a test screen. $(E)$ Strategy for recovering maternally interacting mutations. Although similar to the screen described in $A$, the induced mutation and the wimp mutation must both be present in the female (st ${ }^{\circ}$ wimp Sb) to see an interaction. $(F-H)$ Cuticle phenotypes of embryos from wimp/"maternal mutant" transheterozygous mothers representing three different mutations isolated in a test screen. One mutation, 8.14, shows similar maternal and zygotic phenotypes: The maternal phenotype is variable $(H$ and $I)$, but the homozygous zygotic phenotype is consistent $(J)$. Anterior is uppermost in all cases. 
(1986), using biotinylated secondary antibodies and avidin/biotin/horseradish peroxidase (HRP) complexes (Vector Laboratories, Inc.). The antibodies used in this study were generously provided by the following: H. Krause (rabbit anti-ftz antibodies; Krause et al. 1988); W. Driever and C. Nüsslein-Volhard (monoclonal anti-bcd antibodies; Driever and Nüsslein-Volhard 1988a); M. Frasch (rabbit anti-eve antibodies; Frasch et al. 1987); U. Gaul and H. Jäckle (rabbit anti-Kr antibodies; Gaul et al. 1987); D. Tautz (rabbit anti-hb antibodies; Tautz 1988); M. Wilcox (monoclonal anti-en antibodies; LMB, Cambridge, UK); C. Rushlow and M. Levine (guinea pig anti-zen antibodies; Columbia University, NY); S. Roth and C. Nüsslein-Volhard (rabbit anti-twi antibodies; Tübingen, Germany); and $\mathrm{H}$. Durbin (monoclonal anti- $\beta$-gal antibodies; $4 \mathrm{C7}$; ICRF Lincolns Inn Fields, UK). All secondary antibodies were obtained from Jackson ImmunoResearch Labs (West Grove, PA). Stained embryos were dehydrated in $100 \%$ ethanol and mounted under a coverslip in methacrylate mounting medium (JB-4, Polysciences) that was polymerized under $\mathrm{CO}_{2}$ for $1-2 \mathrm{hr}$ at room temperature.

For accurate comparisons of wild-type and wimp staining levels, embryos from wimp heterozygous and osk homozygous mothers were mixed before fixation and processed together (Lehmann and Nüsslein-Volhard 1986; Driever and Nüsslein-Volhard $1988 \mathrm{~b}$ ). The latter were recognized by their lack of pole cells. Embryos derived from osk-homozygous mothers have altered patterns but wild-type levels of segmentation gene protein.

\section{In situ hybridization}

Whole-mount immunohistochemical in situ hybridization was performed essentially by the protocol of Tautz and Pfiefle (1989). Radiochemical in situ hybridization using ${ }^{35} \mathrm{~S}$-labeled RNA probes was performed as described by Ingham et al. (1985).

\section{Isolation of wimp revertants}

wimp Sb/TM3, Ser males were aged for 3-4 days, $\gamma$-irradiated with 6000 rads, and outcrossed to TM1/TM3, Ser flies. Resulting wimp $S b / T M 3$ female progeny were mated to $D f(3 R) S c b / T M 3$, $S b$ Ser males. In a second screen, wimp $S b / T M 3$, Ser females were irradiated and mated directly to $D f(3 R) S c b / T M 3, S b$ Ser males. In both cases, the only viable class of progeny is wimp $\mathrm{Sb} / \mathrm{ftz}$, and these will die unless the wimp chromosome has reverted. From 2550 male and an estimated 7300 female $\gamma$-irradiated chromosomes, we recovered three such chromosomes. One of these, wimpRQ, also fails to interact with eve, $h$, and $K r$, excluding the possibility that it represents a nonspecific suppressor mutation (e.g., a duplication of the $f t z^{+}$gene). The other two chromosomes are specific for $f t z$ but have not been tested further.

\section{Genetic mapping and complementation tests}

The original wimp allele was mapped by recombination between $c u$ and $s r$, at genetic map position $54.0 \mathrm{cM}$ and within $D p$ (3R) $\operatorname{kar}^{51}$ (P. Ingham, unpubl.). Deletions and duplications for the region were then tested (Fig. 6A). Crosses were done reciprocally to avoid ambiguities caused by the dominant maternal effect of the wimp allele. The same approach was used for the complementation crosses involving the wimpRQ chromosome.

Interactions with the wimp chromosome were performed as shown in Figures 1, A and B, and 3D. Zygotically active genes on the second or third chromosome were tested as wimp/ $+\mathrm{fe}$ males crossed to heterozygous mutant males. Zygotically active genes on the $\mathrm{X}$ chromosome and maternally active genes were tested as transheterozygous females outcrossed to wild-type males.

\section{Germ-line transformation}

Cosmids $\cos 15, \cos 92, \cos 50$, and $\cos 731$ were isolated in a chromosomal walk by R.L. Kelley (pers. comm.) and are recombinants in the transformation vector cosP neo (Steller and Pirrotta 1985). They were injected $(500 \mu \mathrm{g} / \mathrm{ml})$ into bw; st embryos, together with $p \pi 25.7^{\text {wc }}$ helper plasmid $(100 \mu \mathrm{g} / \mathrm{ml})$ (Spradling 1986). Hatched $G_{0}$ flies were outcrossed to wild type and selected on our standard medium supplemented with Geneticin G418 sulfate (1-1.5 mg/ml, according to batch) (GIBCO-BRL). Putative transformed progeny $\left(\mathrm{G}_{1}\right)$ were crossed to $b w$; st and reselected on G418 food, mapping the insert to a specific chromosome. Homozygous or balanced stocks of transformed progeny were then made by conventional means. Transformants were confirmed by polymerase chain reaction (Erlich 1989) using primers specific to the neo portion of the transformation vector.

\section{Histology of homozygous wimp embryos}

Embryos were fixed as for in situ hybridization, devitellinized in MEOH/EGTA, and postfixed in $4 \%$ paraformaldehyde/ $\%$ glutaraldehyde in PBS. Embryos were then rinsed in PBS before incubating in $2 \%$ osmium tetroxide for $30 \mathrm{~min}$ at $4^{\circ} \mathrm{C}$. Embryos were dehydrated and incubated for $10 \mathrm{~min}$ in propylene oxide, followed by $1 \mathrm{hr}$ in propylene oxide/araldite $(1: 1)$ at room temperature. Embryos were infused with araldite overnight at room temperature and transferred to fresh araldite before curing at $50^{\circ} \mathrm{C}$ for $24-36 \mathrm{hr}$. Five-micron sections were mounted on gelatinized slides, stained with toluidine blue $(1 \%$ in $1 \%$ borax $)$, and mounted under a coverslip in Permount mountant (BDH).

\section{Screening for novel interacting mutations}

A preliminary screen using 744 zygotically and 589 maternally mutated $b w$; st chromosomes was performed as described in Figure $8(A, E)$. Males were fed overnight on $25 \mathrm{~mm}$ EMS in $1 \%$ sucrose, as described previously (Grigliatti 1986). Mutations were identified by screening embryos from individual mutagenized chromosomes on apple juice plates (Wieschaus and Nüsslein-Volhard 1986). Mutations were mapped by segregation of the induced mutant phenotype with the $b w$ or st markers, and balanced stocks were established. Complementation crosses with wimp and wimpRQ were performed as described above for the chromosomal deficiencies.

\section{Acknowledgments}

We thank Phil Ingham for sharing his initial observations on the nature of the wimp mutation, Mark Mortin for sharing unpublished data and many fruitful discussions, Suki Parks for suggestions and numerous helpful discussions, Rick Kelley for sharing unpublished data and for "cosmids that performed as advertised," Barbara Hamilton and Arno Greenleaf for sharing unpublished data and RpII140 transformant stocks, and Paul Martin for tuition in and ingredients for araldite histology. We also thank W. Driever, H. Durbin, M. Frasch, U. Gaul, H. Jäckle, H. Krause, M. Levine, C. Nüsslein-Volhard, C. Rushlow, S. Roth, D. Tautz, and M. Wilcox for antibodies; and L. Bell, S. Celniker, A. Greenleaf, B. Hamilton, Y. Hiromi, R. Kelley, R. Lehmann, L. Manseau, M. Mortin, C. Nüsslein-Volhard, S. Parks, D. Weigel, E. Wieschaus, and R. Yip for the fly stocks and DNA clones used in this study. We are grateful to Mark Mortin, 
Suki Parks, Andy Copp, and Karen Downs for critical reading and comments on the manuscript. We thank our colleagues in the lab (Kate Hooper, Sheena Pinchin, Mark Wainwright, Michael Lardelli, Guy Riddihough, and Ilan Davis), at the ICRF Developmental Biology Unit, at Caltech, and in the fly groups at Princeton for suggestions and stimulating discussions during the course of this work. S.M.P. was supported by a postdoctoral fellowship from the Helen Hay Whitney Foundation.

The publication costs of this article were defrayed in part by payment of page charges. This article must therefore be hereby marked "advertisement" in accordance with 18 USC section 1734 solely to indicate this fact.

\section{References}

Akam, M. 1987. The molecular basis for metameric pattern in the Drosophila embryo. Development 101: 1-22.

Anderson, K.V. and C. Nüsslein-Volhard. 1986. Dorsal-group of genes of Drosophila. Symp. Soc. Dev. Biol. 43: 177-194.

Anderson, K.V., G. Jürgens, and C. Nüsslein-Volhard. 1985. The establishment of dorsal-ventral polarity in the Drosophila embryo: Genetic studies on the role of the Toll gene product. Cell 42: 779-789.

Benezra, R., R.L. Davis, D. Lockshon, D.L. Turner, and H. Weintraub. 1990. The protein Id: A negative regulator of helixloop-helix DNA binding proteins. Cell 61: 49-59.

Biggin, M.D. and R. Tjian. 1989. Transcription factors and the control of Drosophila development. TIGS 5: 377-383.

Boswell, R.E. and A.P. Mahowald. 1985. tudor, a gene required for assembly of the germ plasm in Drosophila melanogaster. Cell 43: 97-104.

Carroll, S.B. and M.P. Scott. 1986. Zygotically active genes that affect the spatial expression of the fushi tarazu segmentation gene during early Drosophila embryogenesis. Cell 45: 113-226.

Carroll, S.B., S. DiNardo, P.H. O'Farrell, R.A.H. White, and M.P. Scott. 1988. Temporal and spatial relationships between segmentation and homeotic gene expression in Drosophila embryos: Distributions of the fushi tarazu, engrailed, Sex combs reduced, Antennapedia, and Ultrabithorax. Genes \& Dev. 2: 350-360.

Cline, T.W. 1980. Maternal and zygotic sex-specific gene interactions in Drosophila melanogaster. Genetics 96: 903-926.

- 1986. A female-specific lesion in an X-linked positive regulator of the Drosophila sex determination gene, Sex-lethal. Genetics 113: 641-663.

1988. Evidence that sisterless- $a$ and sisterless- $b$ are two of several discrete "numerator elements" of the X/A sex determination signal in Drosophila that switch $\mathrm{Sxl}$ between two alternative stable expression states. Genetics 119: 829862.

Cooley, L., C. Berg, and A. Spradling. 1988. Controlling P element insertional mutagenesis. Trends Genet. 4: 254-258.

Dearolf, C.R., J. Topol, and C.S. Parker. 1989. Transcriptional control of Drosophila fushi tarazu zebra stripe expression. Genes \& Dev. 3: 384-398.

Driever, W. and C. Nüsslein-Volhard. 1988a. A gradient of bicoid protein in Drosophila embryos. Cell 54: 83-93.

- 1988b. The bicoid protein determines position in the Drosophila embryo in a concentration-dependent manner. Cell 54: 95-104.

1989. The bicoid protein is a positive regulator of hunchback transcription in the early Drosophila embryo. Nature 337: 138-143.

Driever, W., V. Siegel, and C. Nüsslein-Volhard. 1990. Autonomous determination of anterior structures in the early
Drosophila embryo by the bicoid morphogen. Development 109: 811-820.

Driever, W., G. Thoma, and C. Nüsslein-Volhard. 1989. Determination of spatial domains of zygotic gene expression in the Drosophila embryo by the affinity of binding sites for the bicoid morphogen. Nature 340: 363-367.

Edgar, B.A., M.P. Weir, G. Schubiger, and T. Kornberg. 1986. Repression and turnover pattern fushi tarazu RNA in the early Drosophila embryo. Cell 47: 747-754.

Erlich, H.A. 1989. PCR technology. Stockton Press, New York.

Foe, V.A. and B.M. Alberts. 1983. Studies of nuclear and cytoplasmic behaviour during the five mitotic cycles that precede gastrulation in Drosophila embryogenesis. I. Cell Sci. 61: $31-70$.

Frasch, M. and M. Levine. 1987. Complementary patterns of even-skipped and fushi tarazu expression involve their differential regulation by a common set of segmentation genes in Drosophila. Genes \& Dev. 1: 981-995.

Frasch, M., T. Hoey, C. Rushlow, H. Doyle, and M. Levine. 1987. Characterisation and localization of the even-skipped protein of Drosophila. EMBO J. 6: 749-759.

Frohnhöfer, H.G. and C. Nüsslein-Volhard. 1986. Organization of anterior pattern in the Drosophila embryo by the maternal gene bicoid. Nature 324: 120-125.

- 1987. Maternal genes required for the anterior localization of bicoid activity in the embryos of Drosophila. Genes \& Dev. 1: 880-890.

Gaul, U., E. Seifert, R. Schuh, and H. Jäckle. 1987. Analysis of Krüppel protein distribution during early Drosophila development reveals post-transcriptional regulation. Cell 50: 639-647.

Grigliatti, T. 1986. Mutagenesis. In Drosophila, a practical approach (ed. D.B. Roberts), pp. 39-58. IRL Press, Oxford.

Halazonetis, T.D., K. Georgopolous, M.E. Greenberg, and P. Leder. 1988. c-Jun dimerizes with itself and with c-Fos, forming complexes of different DNA binding affinities. Cell 55: 917924.

Han, K., M.S. Levine, and J.L. Manley. 1989. Synergistic activation and repression of transcription by Drosophila homeobox proteins. Cell 56: 573-583.

Hayashi, S. and M.P. Scott. 1990. What determines the specificity of action of Drosophila homeodomain proteins? Cell 63: 883-894.

Hiromi, Y. and W.J. Gehring. 1987. Regulation and function of the Drosophila segmentation gene fushi tarazu. Cell 50: $963-974$.

Hiromi, Y., A. Kuroiwa, and W.J. Gehring. 1985. Control elements of the Drosophila segmentation gene fushi tarazu. Cell 43: 603-613.

Howard, K. and P. Ingham. 1986. Regulatory interactions between the segmentation genes fushi tarazu, hairy and engrailed in the Drosophila blastoderm. Cell 44: 949-957.

Hülskamp, M., C. Pfeifle, and D. Tautz. 1990. A morphogenetic gradient of hunchback protein organises the expression of the gap genes Krüppel and knirps in the early Drosophila embryo. Nature 346: 577-580.

Hülskamp, M., C. Schröder, C. Pfeifle, H. Jäckle, and D. Tautz. 1989. Posterior segmentation of the Drosophila embryo in the absence of a maternal posterior organizer gene. Nature 338: 629-632.

Ingham, P. 1983. Differential expression of bithorax complex genes in the absence of the extra sex combs and trithorax genes. Nature 306: 591-593.

- 1988. The molecular genetics of embryonic pattern formation in Drosophila. Nature 335: 25-34.

Ingham, P.W., K.R. Howard, and D. Ish-Horowicz. 1985. Tran- 
scription pattern of the Drosophila segmentation gene hairy. Nature 318: 439-445.

Ingham, P.W., D. Ish-Horowicz, and K.R. Howard. 1986. Correlative changes in homeotic and segmentation gene expression in Krüppel mutant embryos of Drosophila. EMBO J. 5: 1659-1665.

Irish, V.F. and W.M. Gelbart. 1987. The decapentaplegic gene is required for dorsal-ventral patterning of the Drosophila embryo. Genes \& Dev. 1: 868-879.

Irish, V., R. Lehmann, and M. Akam. 1989. The Drosophila posterior-group gene nanos functions by repressing hunchback activity. Nature 338: 646-648.

Jaynes, J.B. and P.H. O'Farrell. 1988. Activation and repression of transcription by homeodomain-containing proteins that bind a common site. Nature 336: 744-749.

Jürgens, G., E. Wieschaus, C. Nüsslein-Volhard, and H. Kluding. 1984. Mutations affecting the pattern of the larval cuticle in Drosophila melanogaster. II. Zygotic loci on the third chromosome. Wilhelm Roux's Arch. Dev. Biol. 193: 283-295.

Kouzarides, T. and E. Ziff. 1988. The role of the leucine zipper in the fos-iun interaction. Nature 336: 646-651.

Krause, H.M., R. Klemenez, and W.J. Gehring. 1988. Expression, modification, and localization of the fushi tarazu protein in Drosophila embryos. Genes \& Dev. 2: 1021-1036.

Lawrence, P.A., P. Johnston, P. Macdonald, and G. Struhl. 1987. Borders of parasegments in Drosophila embryos are delimited by the fushi tarazu and even-skipped genes. Nature 328: $440-442$.

Lehmann, R. 1988. Phenotypic comparison between maternal and zygotic genes controlling the segmental pattern of the Drosophila embryo. Development (suppl). 104: 17-27.

Lehmann, R. and C. Nüsslein-Volhard. 1986. Abdominal segmentation, pole cell formation and embryonic polarity require the localised activity of oskar, a maternal gene in Drosophila. Cell 47: 141-152.

- 1987. Involvement of the pumilio gene in the transport of an abdominal signal in the Drosophila embryo. Nature 329: $167-170$.

Levine, M. and T. Hoey. 1988. Homeobox proteins as sequencespecific transcription factors. Cell 55: 537-540.

Lewis, E.B. 1978. A gene complex controlling segmentation in Drosophila. Nature 276: 565-570.

Lindsley, D.L. and G. Zimm. 1987. The genome of Drosophila melanogaster, Part 3: Rearrangements. Dros. Inf. Serv. 65.

Macdonald, P.M. and G. Struhl. 1986. A molecular gradient in early Drosophila embryos and its role in specifying body pattern. Nature 324: 537-545.

Manseau, L.J. and T. Schüpbach. 1989. cappuccino and spire: Two unique maternal-effect loci required for both anteroposterior and dorsoventral patterns of the Drosophila embryo. Genes \& Dev. 3: 1437-1452.

Mitchell, P.J. and R. Tjian. 1989. Transcriptional regulation in mammalian cells by sequence-specific DNA binding proteins. Science 245: 371-378.

Mohler, J. and E. Wieschaus. 1986. Dominant maternal-effect mutations of Drosophila melanogaster causing the production of double-abdomen embryos. Genetics 112: 803-822.

Mortin, M.A. 1990. Use of second-site suppressor mutations in Drosophila to identify components of the transcriptional machinery. Proc. Natl. Acad. Sci. 87: 4864-4868.

Mortin, M.A. and G. Lefevre. 1981. An RNA polymerase II mutation in Drosophila melanogaster that mimics Ultrabithorax. Chromosoma 82: 237-247.

Murre, C., P.S. McCaw, H. Vaessin, M. Caudy, L.Y. Jan, Y.N. Jan, C.V. Cabrera, J.N. Buskin, S.D. Hauschka, A.B. Lassar, H. Weintraub, and D. Baltimore. 1989. Interactions between heterologous helix-loop-helix proteins generate complexes that bind specifically to a common DNA sequence. Cell 58: $537-544$.

Nakabeppu, Y., K. Ryder, and D. Nathans. 1988. DNA binding of three murine jun proteins: Stimulation by fos. Cell 55: 907-915.

Nüsslein-Volhard, C. 1979. Maternal-effect mutations that alter the spatial coordinates of the embryo of Drosophila melanogaster. Symp. Soc. Dev. Biol. 37: 185-211.

Nüsslein-Volhard, C. and S. Roth. 1989. Axis determination in insect embryos. Cellular basis of morphogenesis. Ciba Found. Symp. 144: 37-64.

Nüsslein-Volhard, C. and E. Wieschaus. 1980. Mutations affecting segment number and polarity in Drosophila. Nature 287: 795-801.

Nüsslein-Volhard, C., H.G. Frohnhöfer, and R. Lehmann. 1987. Determination of anteroposterior polarity in Drosophila. Science 238: 1675-1681.

Nüsslein-Volhard, C., E. Wieschaus, and H. Kluding. 1984. Mutations affecting the pattern of the larval cuticle in Drosophila melanogaster I. Zygotic loci on the second chromosome. Wilhelm Roux's Arch. Dev. Biol. 193: 267-282.

Nüsslein-Volhard, C., M. Lohs-Schardin, K. Sander, and C. Cremer. 1980. A dorso-ventral shift of embryonic primordia in a new maternal effect mutant of Drosophila. Nature 283: 474-476.

Odenwald, W.F., J. Garbern, H. Arnheiter, E. Tournier-Lasserve, and R.A. Lazzarini. 1989. The Hox-1.3 homeo box protein is a sequence-specific DNA-binding phosphoprotein. Genes \& Dev. 3: 158-172.

O'Kane, C.J. and W.J. Gehring. 1987. Detection in situ of genomic regulatory elements in Drosophila. Proc. Nat. Acad. Sci. 84: 9123-9127.

Pankratz, M.J., M. Hoch, E. Seifert, and H. Jäckle. 1989. Krüppel requirement for knirps enhancement reflects overlapping gap gene activities in the Drosophila embryo. Nature 341: 337-340.

Pankratz, M.J., E. Seifert, N. Gerwin, B. Billi, U. Nauber, and H. Jäckle. 1990. Gradients of Krüppel and knirps gene products direct pair-rule gene stripe patterning in the posterior region of the Drosophila embryo. Cell 61: 309-317.

Parker, C.S. 1989. Transcription factors. Curr. Opin. Cell Biol. 1: 512-518.

Parkhurst, S.M., D. Bopp, and D. Ish-Horowicz. 1990. X : A ratio, the primary sex determining signal in Drosophila, is transduced by helix-loop-helix proteins. Cell 63: 1179-1191.

Parkhurst, S.M., D.A. Harrison, M.P. Remington, C. Spana, R.L. Kelley, R.S. Coyne, and V.G. Corces. 1988. The Drosophila $s u(H w)$ gene, which controls the phenotypic effect of the gypsy transposable element, encodes a putative DNA-binding protein. Genes \& Dev. 2: 1205-1215.

Perrimon, N., L. Engstrom, and A.P. Mahowald. 1984. Analysis of the effects of zygotic lethal mutations on the germ line functions in Drosophila. Dev. Biol. 105: 404-414.

Ptashne, M. 1988. How eukaryotic transcriptional activators work. Nature 335: 683-689.

Roth, S., D. Stein, and C. Nüsslein-Volhard. 1989. A gradient of nuclear localization of the dorsal protein pattern determines dorsoventral pattern in the Drosophila embryo. Cell 59: 1189-1202.

Rushlow, C.A., K. Han, J.L. Manley, and M. Levine. 1989. The graded distribution of the dorsal morphogen is initiated by selective nuclear transport in Drosophila. Cell 59: 11651177.

Santoro, C., N. Mermod, P.C. Andrews, and R. Tjian. 1988. A family of human CCAAT-box-binding proteins active in 
transcription and DNA replication: Cloning and expression of multiple cDNAs. Nature 334: 218-224.

Schüpbach, T. and E. Wieschaus. 1986. Maternal-effect mutations altering the anterior-posterior pattern of the Drosophila embryo. Wilhelm Roux's Arch. Dev. Biol. 195: 302317.

Scott, M.P. and S.B. Carroll. 1987. The segmentation and homeotic gene network in early Drosophila development. Cell 51: 689-698.

Scott, M.P. and P.H. O'Farrell. 1986. Spatial programming of gene expression in early Drosophila embryogenesis. Annu. Rev. Cell. Biol. 2: 49-80.

Simpson, P. 1983. Maternal-zygotic gene interactions during formation of the dorsoventral pattem in Drosophila embryos. Genetics 105: 615-632.

Spradling, A.C. 1986. P element-mediated transformation. In Drosophila, a practical approach (ed. D.B. Roberts), pp. 175197. IRL Press, Oxford.

Steller, H. and V. Pirrotta. 1985. A transposable $P$ vector that confers G418 resistance to Drosophila larvae. EMBO $\mathrm{J}$. 4: $167-171$.

Steward, R. 1987. dorsal, an embryonic polarity gene in Drosophila, is homologous to the vertebrate proto-oncogene, $c$-rel. Science 238: 692-694.

- 1989 . Relocalization of the dorsal protein from the cytoplasm to the nucleus correlates with its function. Cell 59: 1179-1188.

Steward, R., S.B. Zusman, L.H. Huang, and P. Schedl. 1988. The dorsal protein is distributed in a gradient in early Drosophila embryos. Cell 55: 487-495.

Struhl, G. 1989a. Different strategies for organizing anterior and posterior body pattern in Drosophila embryos. Nature 338: 741-744.

- $1989 \mathrm{~b}$. Morphogen gradients and the control of body pattern in insect embryos. Cellular basis of morphogenesis Ciba Found. Symp. 144: 65-91.

Struhl, G., K. Struhl, and P.M. Macdonald. 1989. The gradient morphogen bicoid is a concentration-dependent transcriptional activator. Cell 57: 1259-1273.

Struhl, K. 1989. Helix-turn-helix, zinc-finger, and leucine-zipper motifs for eukaryotic transcriptional regulatory proteins. Trends Biochem. Sci. 14: 137-140.

Sullivan, W. 1987. Independence of fushi tarazu expression with respect to cellular density in Drosophila embryos. Nature 327: 164-167.

Tautz, D. 1988. Regulation of the Drosophila segmentation gene hunchback by two maternal morphogenetic centres. Nature 332: 281-284.

Tautz, D. and C. Pfeifle. 1989. A non-radioactive in situ hybridization method for the localization of specific RNAs in Drosophila embryos reveals translational control of the segmentation gene hunchback. Chromosoma 98: 81-85.

Tricoire, H. 1988. Dominant maternal interactions with Drosophila segmentation genes. Wilhelm Roux's Arch. Dev. Biol. 197: 115-123.

Wakimoto. B.T., F.R. Turner, and T. Kaufman. 1984. Defects in embryogenesis in mutants associated with the Antennapedia gene complex of Drosophila melanogaster. Dev. Biol. 102: $147-172$.

Weigel, D., G. Jürgens, M. Klingler, and H. Jäckle. 1990. Two gap genes mediate maternal terminal pattern information in Drosophila. Science 248: 495-498.

Wieschaus, E. and C. Nüsslein-Volhard. 1986. Looking at embryos. In Drosophila, a practical approach (ed. D.B. Roberts), pp.199-226. IRL Press, Oxford.

Wieschaus, E. and D. Sweeton. 1988. Requirements for X-linked zygotic gene activity during cellularization of early Drosophila embryos. Development 104: 483-493.

Wieschaus, E., C. Nüsslein-Volhard, and G. Jürgens. 1984. Mutations affecting the pattern of the larval cuticle in Drosophila melanogaster. I. Zygotic loci on the $\mathrm{X}$ chromosome and the fourth chromosome. Wilhelm Roux's Arch. Dev. Biol. 193: 296-307. 


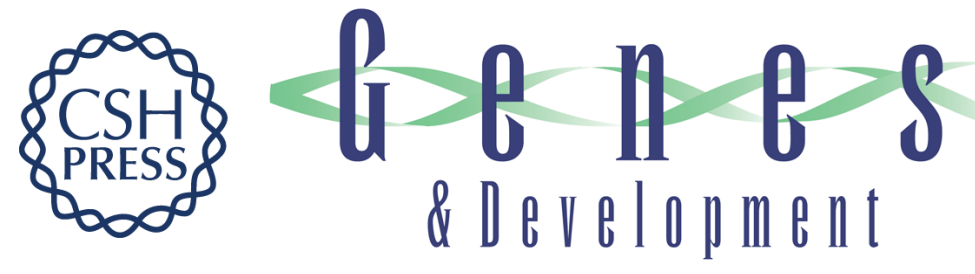

\section{wimp, a dominant maternal-effect mutation, reduces transcription of a specific subset of segmentation genes in Drosophila.}

S M Parkhurst and D Ish-Horowicz

Genes Dev. 1991, 5:

Access the most recent version at doi:10.1101/gad.5.3.341

References This article cites 95 articles, 24 of which can be accessed free at: http://genesdev.cshlp.org/content/5/3/341.full.html\#ref-list-1

License

Email Alerting

Service

Receive free email alerts when new articles cite this article - sign up in the box at the top right corner of the article or click here.

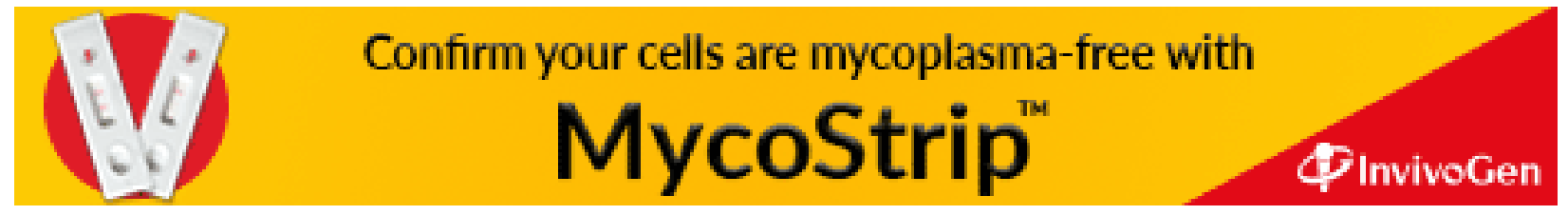

